\title{
Apamin-Sensitive Small Conductance Calcium-Activated Potassium Channels, through their Selective Coupling to Voltage-Gated Calcium Channels, Are Critical Determinants of the Precision, Pace, and Pattern of Action Potential Generation in Rat Subthalamic Nucleus Neurons In Vitro
}

\author{
Nicholas E. Hallworth, ${ }^{1}$ Charles J. Wilson, ${ }^{2}$ and Mark D. Bevan ${ }^{3}$ \\ ${ }^{1}$ University of Tennessee, Anatomy and Neurobiology, Memphis, Tennessee 38163, ${ }^{2}$ Division of Life Science, University of Texas, San Antonio, Texas \\ 78294, and ${ }^{3}$ Department of Physiology, Feinberg School of Medicine, Northwestern University, Chicago, Illinois 60611-3008
}

\begin{abstract}
Distinct activity patterns in subthalamic nucleus (STN) neurons are observed during normal voluntary movement and abnormal movement in Parkinson's disease (PD). To determine how such patterns of activity are regulated by small conductance (SK) calcium-activated potassium channels $\left(\mathrm{K}_{\mathrm{Ca}}\right)$ and voltage-gated calcium $\left(\mathrm{Ca}_{\mathrm{v}}\right)$ channels, STN neurons were recorded in the perforated patch configuration in slices, [which were prepared from postnatal day $16(\mathrm{P} 16)-\mathrm{P} 30$ rats and held at $37^{\circ} \mathrm{C}$ ] and then treated with the $\mathrm{SK} \mathrm{K}_{\mathrm{Ca}}$ channel antagonist apamin or the $\mathrm{SK} \mathrm{K}_{\mathrm{Ca}}$ agonist 1-ethyl-2-benzimidazolinone or the $\mathrm{Ca}_{\mathrm{v}}$ channel antagonists $\omega$-conotoxin GVIA (Ca 2.2 selective) or nifedipine $\left(\mathrm{Ca}_{\mathrm{v}} 1.2-1.3\right.$-selective). In other experiments, fura-2 was introduced as an indicator of intracellular calcium dynamics.

A component of the current underlying single-spike afterhyperpolarization was sensitive to apamin, phase-locked to calcium entry via $\mathrm{Ca}_{\mathrm{v}} 2.2$ channels, and necessary for precise, autonomous, single-spike oscillation. $\mathrm{SK} \mathrm{K}_{\mathrm{Ca}} / \mathrm{Ca}_{\mathrm{v}} 2.2$ channel coupling did not underlie spike-frequency adaptation but limited activity in response to current injection by encoding the accumulation of intracellular calcium, maintained the characteristic sigmoidal frequency-intensity relationship and generated a post-train afterhyperpolarization. In addition, SK $\mathrm{K}_{\mathrm{Ca}}$ channels terminated rebound burst activity more effectively in neurons with short-duration bursts $(<100 \mathrm{msec})$ than neurons with long-duration bursts $\left(>100 \mathrm{msec}\right.$ ), presumably through their activation by $\mathrm{Ca}_{\mathrm{v}} 3$ channels. $\mathrm{Ca}_{\mathrm{v}} 1.2-1.3$ channels were not strongly coupled to $\mathrm{SK} \mathrm{K}_{\mathrm{Ca}}$ channels and therefore supported secondary range and long-duration rebound burst firing. In summary, SK $\mathrm{K}_{\mathrm{Ca}}$ channels play a fundamental role in autonomous, driven, and rebound activity and oppose the transition from autonomous, rhythmic, single-spike activity to burst firing in STN neurons.
\end{abstract}

Key words: basal ganglia; oscillation; afterhyperpolarization; rebound burst; apamin; EBIO

\section{Introduction}

The glutamatergic subthalamic nucleus (STN) is a key component of the basal ganglia, a collection of subcortical brain nuclei involved in motor, sensory, associative, and limbic functions (for review, see Wise et al., 1996). Under resting conditions, the tonic activity of the STN drives, in part, the tonic activity of its target nuclei. During movement, sporadic high-frequency activity of the STN plays a pivotal role in the response of the basal ganglia to cortical and thalamic activation (Kitai and Deniau, 1981; Mat-

Received Jan. 16, 2003; revised June 24, 2003; accepted June 30, 2003.

This work was supported by National Institute of Neurological Disorders and Stroke Grants NS41280 (M.D.B.), NS20702 (M.D.B.), NS047085 (M.D.B. and C.J.W.), and NS26473 (C.J.W.). Nicholas Hallworth is in receipt of a Center for Neuroscience Predoctoral Fellowship at the University of Tennessee. We thank Drs. William Armstrong, Jay Callaway, and Robert Foehring for helpful discussions throughout this study.

Correspondence should be addressed to Dr. Mark D. Bevan, Department of Physiology-M211, Feinberg School of Medicine, Northwestern University, 303 East Chicago Avenue, Chicago, IL 60611-3008. E-mail:m-bevan@northwestern.edu. Copyright $\odot 2003$ Society for Neuroscience $\quad 0270-6474 / 03 / 237525-18 \$ 15.00 / 0$ sumara et al., 1992; Fujimoto and Kita, 1993; Wichmann et al., 1994; Mouroux et al., 1995). In Parkinson's disease (PD), abnormal, rhythmic, bursting activity of the STN plays a key role in the expression of symptoms (Bergman et al., 1994; Levy et al., 2000, 2002). Indeed, therapies like high-frequency electrical stimulation of the STN have been successful in ameliorating the symptoms of PD (for review, see Benabid et al., 2001).

In recent years, several groups have defined intrinsic membrane properties of STN neurons in vitro that are likely to contribute to their pattern of activity and integration of synaptic input in vivo (Nakanishi et al., 1987; Beurrier et al., 1999, 2000; Bevan and Wilson, 1999; Song et al., 2000; Wigmore and Lacey, 2000; Otsuka et al., 2001; Bevan et al., 2002; Zhu et al., 2002; Baufreton et al., 2003; Do and Bean, 2003). These properties include: (1) autonomous, rhythmic single-spike activity, (2) the ability to fire at high frequencies $(100-500 \mathrm{~Hz}),(3)$ a primary range of activity $(<40 \mathrm{~Hz})$ that is approximately half as sensitive 
to input as a secondary range of activity $(>40 \mathrm{~Hz})$, and (4) heterogeneous rebound burst activity. Further analyses of the ion channels underlying these properties will be critical for our understanding of the function and dysfunction of the STN and for the development and refinement of treatments for PD that are based on the modulation of STN activity.

In recent whole-cell patch clamp recording studies of STN neurons, calcium entry via voltage-gated calcium $\left(\mathrm{Ca}_{\mathrm{v}}\right)$ channels predominantly activated small conductance (SK) calciumactivated potassium channels $\left(\mathrm{K}_{\mathrm{Ca}}\right)$ channels, which played a pivotal, largely suppressive role in shaping activity or activated nonspecific cation channels, which augmented activity (Bevan and Wilson, 1999; Beurrier et al., 1999, 2000; Otsuka et al., 2001). Because the whole-cell configuration of the patch-clamp technique can introduce alien calcium buffers and anions that disrupt intracellular calcium dynamics (Neher and Augustine, 1992; Zhang et al., 1995; Helmchen and Tank, 1999; Velumian and Carlen, 1999) and block intrinsic ion channels (Zhang et al., 1994; Velumian et al., 1997), we applied the perforated patchclamp technique, with gramicidin as the pore-forming substance (Myers and Haydon, 1972; Abe et al., 1994; Kyrozis and Reichling, 1995) to study in a more definitive manner the role of apamin-sensitive $\mathrm{SK} \mathrm{K}_{\mathrm{Ca}}$ channels and their coupling to $\mathrm{Ca}_{\mathrm{v}}$ channels in STN neurons. In other cases, we deliberately introduced the calcium indicator fura- 2 to track the dynamic changes in intracellular calcium (Grynkiewicz et al., 1985; Lev-Ram et al., 1992) that are presumably related to the activation of SK $K_{\mathrm{Ca}}$ channels.

\section{Materials and Methods \\ Electrophysiology}

Slice preparation. Electrophysiological studies were performed on brain slices prepared from 43 16- to 30-d-old Sprague Dawley rats. Animals were deeply anesthetized with a mixture of ketamine and xylazine and perfused transcardially with $10-40 \mathrm{ml}$ of ice-cold modified artificial CSF (ACSF), which had been bubbled with $95 \% \mathrm{O}_{2}$ and $5 \% \mathrm{CO}_{2}$ and contained (in mM): 230 sucrose, $2.5 \mathrm{KCl}, 1.25 \mathrm{Na}_{2} \mathrm{HPO}_{4}, 0.5 \mathrm{CaCl}_{2}, 10$ $\mathrm{MgSO}_{4}$, and 10 glucose. The brain was then rapidly removed, blocked in the sagittal plane, glued to the stage of a vibratome (VT 1000S; Leica, Nussloch, Germany), and immersed in ice-cold modified ACSF. Slices containing the STN were cut at a thickness of $300 \mu \mathrm{m}$ and subsequently transferred to a holding chamber, where they were submerged in ACSF, which was bubbled continuously with $95 \% \mathrm{O}_{2}$ and $5 \% \mathrm{CO}_{2}$, maintained at room temperature, and contained (in $\mathrm{mM}$ ): $126 \mathrm{NaCl}, 2.5 \mathrm{KCl}, 1.25$ $\mathrm{Na}_{2} \mathrm{HPO}_{4}, 2 \mathrm{CaCl}_{2}, 2 \mathrm{MgSO}_{4}$, and 10 glucose.

Visualized recording. Single slices were transferred to the recording chamber and perfused continuously $(2-3 \mathrm{ml} / \mathrm{min})$ with oxygenated ACSF at $37^{\circ} \mathrm{C}$. Somatic recordings were made using patch pipettes pulled from standard-wall borosilicate glass (Warner Instruments, Hamden, CT) on a P-97 Flaming-Brown micropipette puller (Sutter Instruments, Novato, CA). Pipettes were filled with a solution containing (in $\mathrm{mm}$ ): 134.1 K-MeSO $, 0.9 \mathrm{KCl}, 3.6 \mathrm{NaCl}, 1 \mathrm{MgCl}_{2} \cdot 6 \mathrm{H}_{2} \mathrm{O}, 10$ HEPES, 0.1 $\mathrm{Na}_{4}$ EGTA, $0.4 \mathrm{Na}_{3}$ GTP, and $2 \mathrm{Mg}_{1.5}$ ATP. The $\mathrm{pH}$ and osmolarity of the pipette solution were 7.3 and 290-300 mOsm, respectively. Gramicidin was added to the pipette solution at an approximate concentration of 20 $\mu \mathrm{g} / \mathrm{ml}<1 \mathrm{hr}$ before seal formation was attempted. The resistance of filled pipettes was between 2.5 and $5 \mathrm{M} \Omega$. Gramicidin was applied because it forms pores that are permeable only to monovalent cations and small neutral molecules like water and thus leaves intact natural calcium dynamics and ion channel properties (Myers and Haydon, 1972; Abe et al., 1994; Kyrozis and Reichling, 1995). A $40 \times$ water-immersion objective (Axioskop; Zeiss, Oberkochen, Germany) was used to examine each slice using infragradient contrast video microscopy (Dodt et al., 1999) (Infrapatch Workstation; Luigs and Neumann, Ratingen, Germany). Perforated recordings were made in current-clamp and voltage-clamp mode using an EPC 9/2.C amplifier (Heka, Lambrecht, Germany), which was operated using Pulse 8.5 software (Heka). Signals were low-pass filtered at a frequency $(1.7-33.3 \mathrm{kHz})$ that was one-third the frequency of digitization $(5-100 \mathrm{kHz})$. Junction potentials were not corrected in the perforated configuration because, in contrast to the whole-cell configuration, the composition of ions in the recorded neuron cannot be assumed to be the same as electrode solution (Marty and Neher, 1983; Neher, 1992; Bevan et al., 2000, 2002). Deliberate or accidental establishment of the whole-cell configuration was recognized as a sudden drop in series resistance, an increase in the amplitude of recorded action potentials, and an $\sim 6 \mathrm{mV}$ offset in membrane potential. The latter was measured as an increase in the threshold for the generation of action potentials that accompanied break-in. The value of the offset was similar to the empirically calculated junction potential between the electrode solution and the external media of $8.7 \mathrm{mV}$ (Neher, 1992; Barry, 1994; Bevan et al., $2000,2002)$. The voltages reported in this paper are therefore likely to be $<3 \mathrm{mV}$ more depolarized than the actual voltages.

While fast capacitive transients of the pipette were nulled on-line, there was no compensation of series resistance or whole-cell capacitance, thus voltage errors attributable to series resistance were subtracted offline as described previously (Bevan et al., 2000).

Drugs. Drugs were diluted in ACSF and bath-applied. Fast synaptic transmission was blocked by the continuous application of $50 \mu \mathrm{M} \mathrm{D}-(-)-2-$ amino-5-phosphonopentanoic acid (APV), $20 \mu \mathrm{M}$ 6,7-dinitroquinoxaline2,3-dione (DNQX), and $20 \mu \mathrm{M}$ SR 95531 hydrobromide (GABAzine) so that the action of SK and $\mathrm{Ca}_{\mathrm{v}}$ channel drugs on intrinsic properties could be studied in isolation from effects on synaptic transmission. Synaptic transmission receptor blockers, 1-ethyl-2-benzimidazolinone (EBIO) and nifedipine were obtained from Tocris (Ellisville, MO). Apamin (1 pm-100 nM) and $\omega$-conotoxin GVIA $(1 \mu \mathrm{M})$ were obtained from Sigma (St. Louis, MO).

Data analysis. Data were analyzed using Pulsefit (Heka) and Origin 5.0 (Microcal, Northampton, MA). Descriptive statistics refer to the mean \pm SEM. Frequency distributions of the experimental data were compared with normal distributions of similar means and SDs, which were constructed using random numbers generated by Statview 5.0 (SAS, Cary, $\mathrm{NC}$ ), using the Kolmogorov-Smirnov (K-S) test. Although datasets were typically not significantly different from a normal distribution, our sample sizes were small. We therefore applied nonparametric statistics, which are subject to fewer assumptions concerning the distribution of data. The means of paired and unpaired experimental datasets were thus compared using the Wilcoxon signed rank (WSR) test and the MannWhitney $U$ test $(\mathrm{M}-\mathrm{W} U$ ) respectively, and probability values $<0.05$ were considered significant.

The dose-response relationship for apamin was characterized in Origin (Microcal) by fitting a single Langmuir isotherm to the plot of mean peak apamin-sensitive current at each concentration of drug. The best fit was assessed over iterative trials in which the variables representing the Hill coefficient and the half-maximal response were permitted to vary.

The frequency and statistical significance of any periodic discharge features induced by apamin were determined using the Lomb algorithm (Kaneoke and Vitek, 1996). Lomb periodograms represent power spectra of the autocorrelograms constructed using 121 spikes of recorded data.

\section{Calcium imaging}

Slices were prepared with, stored in, and perfused with ACSF as described above. Slices were viewed under infrared illumination $(780 \pm 30 \mathrm{~nm})$ using the same CCD camera used for calcium imaging and an Olympus (Melville, NY) BX50WI upright microscope, equipped with DIC optics and a $40 \times(0.8 \mathrm{NA})$ water immersion objective. Micropipettes had resistances of $4-6 \mathrm{M} \Omega$ and were filled with a solution containing (in $\mathrm{mM}$ ): 128.7 K- $\mathrm{MeSO}_{4}$, 2.3 KCl, 10 HEPES, $0.4 \mathrm{Na}_{3} \mathrm{GTP}, 1 \mathrm{MgATP}, 1 \mathrm{Na}_{2} \mathrm{ATP}$, and $0.05-0.2$ fura-2 (Na-salt). The $\mathrm{pH}$ and osmolarity of the pipette solution were 7.3 and 290-300 mOsm, respectively. Current-clamp recordings were made using an active bridge amplifier (Neurodata IR283; Cygnus Technology, Delaware Water Gap, PA). Electrical and optical data were collected synchronously using a single computer. Electrical records were digitized at 16 bit resolution at $10 \mathrm{kHz}$ and corrected for a 5 $\mathrm{mV}$ liquid junction potential (see above). Optical recordings were obtained using a cooled CCD camera (EEV37; Photometrics, Tucson, AZ) in frame transfer mode. Frame rates of $20-50 \mathrm{~Hz}$ were used, depending 
on the size of the field of view. Fluorescence measurements were made using an excitation wavelength of $380 \mathrm{~nm}$ and were corrected for bleaching and autofluorescence. To correct for bleaching, fluorescence measurements were collected while the recorded neuron was held hyperpolarized. These measurements were then filtered at $3 \mathrm{~Hz}$ and subtracted from the fluorescence measurements, which were made when the cell was generating action potentials. Autofluorescence was corrected by subtracting the fluorescence of a nearby region of the slice, which was devoid of fura-containing elements, from the value of $F$ at the beginning of each trial. Changes in the fluorescence of fura- 2 are presented as $\% \delta F / F$, which for changes of $<50 \%$ are related in an almost linear manner to calcium concentration (Lev-Ram et al., 1992). All measurements made in this study were within this range. At an excitation wavelength of $380 \mathrm{~nm}$, the fluorescence of fura-2 decreases with increasing calcium concentration. Therefore, for the sake of clarity, the measurements are plotted as $-\% \delta \mathrm{F} / \mathrm{F}$ so that decreases in fluorescence have the same polarity as increases in calcium concentration.

\section{Results}

SK $K_{\mathrm{Ca}}$ channels underlie a major component of single-spike afterhyperpolarization in STN neurons

To evoke and study in a quantitative manner the currents underlying single-spike afterhyperpolarization, a protocol based on principles outlined by Lancaster and Adams (1986) was applied. This technique has been used successfully to elucidate currents underlying afterhyperpolarization in other systems (Storm, 1989; Wolfart et al., 2001; Wolfart and Roeper, 2002; Faber and Sah, 2002). To induce a single unclamped action potential, the membrane was depolarized from a holding potential of -65 to $20 \mathrm{mV}$ for $10 \mathrm{msec}$. The membrane potential was then returned to -65 $\mathrm{mV}$, and the resulting currents were recorded. This protocol evoked an outward current that apparently peaked $38.9 \pm 5.9$ msec after the termination of the voltage step and decayed within $100-200 \mathrm{msec}(n=16)$ (Fig. $1 A)$. Because the slow decay of this current was similar to those observed for currents carried by SK $\mathrm{K}_{\mathrm{Ca}}$ channels, the current was tested with varying concentrations of the selective SK $\mathrm{K}_{\mathrm{Ca}}$ channel blocker apamin (for review, see Sah, 1996; Vergara et al., 1998; Bond et al., 1999; Sah and Faber, 2002). As predicted, the current was inhibited by low concentrations of apamin (Fig. 1A). To further analyze the apaminsensitivity of the single-spike afterhyperpolarization, the apaminsensitive current was calculated for each concentration of apamin by subtracting the spike-evoked current obtained in apamin from the spike-evoked current observed in control media. At all drug concentrations, the peak amplitudes of subtracted currents were not significantly different from normal distributions of similar means and variance that were generated from random numbers (K-S test; 10 pM: $16.7 \pm 4$ pA, $n=8, p=0.65 ; 100$ pM: $21.3 \pm 6$ $\mathrm{pA}, n=7, p>0.99 ; 500$ pM: $42.1 \pm 7 \mathrm{pA}, n=8, p>0.99 ; 1 \mathrm{nм}:$ $78.7 \pm 9 \mathrm{pA}, n=6, p>0.99 ; 10 \mathrm{nM}: 76.8 \pm 13 \mathrm{pA}, n=5, p>0.99$; 100 nM: $79.0 \pm 12 \mathrm{pA}, n=14, p>0.99)$. Population-subtracted currents were used to construct a dose-response curve, which was reasonably well described by a Hill coefficient of 1.04, was half-maximal at $\sim 246 \mathrm{pm}$, and was clearly saturated at $1 \mathrm{nM}$. The sensitivity of single spike afterhyperpolarization is therefore somewhat intermediate to the sensitivity of identified SK2 $\mathrm{K}_{\mathrm{Ca}}$ channels in slice preparations of cerebellar Purkinje neurons (135 pM; Cingolani et al., 2002) and identified SK3 $\mathrm{K}_{\mathrm{Ca}}$ channels in isolated superior cervical ganglion neurons $(2.3 \mathrm{nM}$; Hosseini et al., 2001) and slice preparations of dorsal vagal neurons (2.2 nM; Pedarzani et al., 2000) and dopaminergic substantia nigra neurons (9.2 nM; Wolfart et al., 2001). Thus, these data suggest that a major component of the single-spike afterhyperpolarization in STN neurons was mediated by SK $\mathrm{K}_{\mathrm{Ca}}$ channels that were com-
A

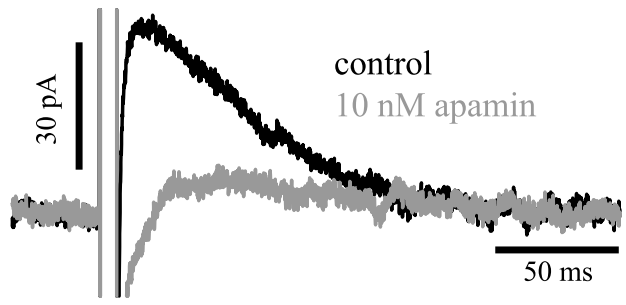

B

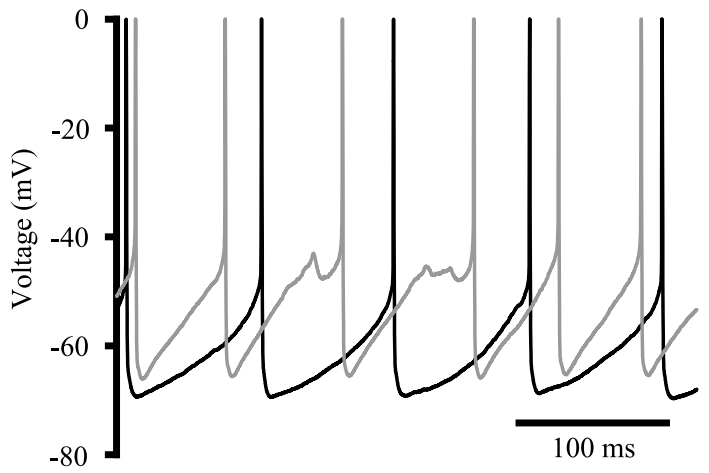

C

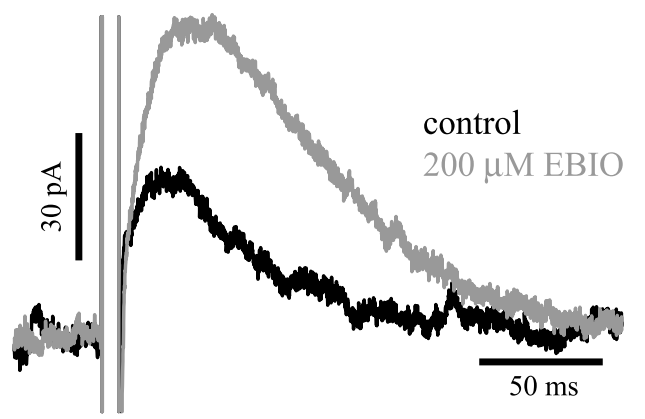

$\mathrm{D}$

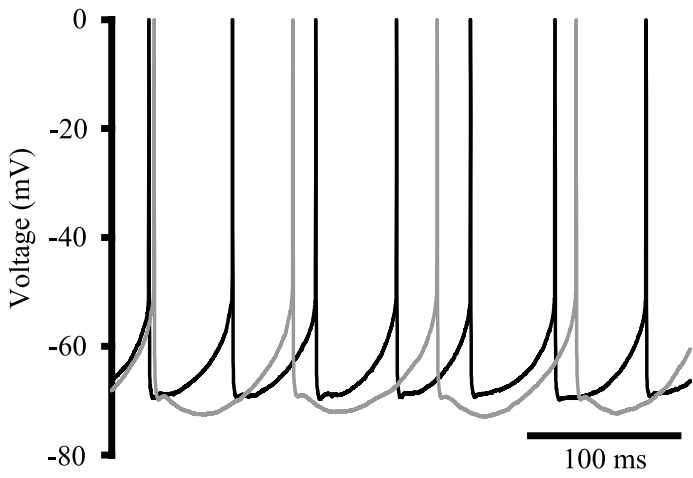

Figure 1. A major component of single-spike afterhyperpolarization is mediated by SK K $\mathrm{Ca}_{\mathrm{Ca}}$ channels. $A, B$, In voltage-clamp, a single unclamped action potential was induced by stepping from a holding potential of -65 to $20 \mathrm{mV}$ for $10 \mathrm{msec}$. The membrane potential was then returned to $-65 \mathrm{mV}$, and the current underlying afterhyperpolarization was studied. The single spike-evoked current was sensitive to apamin. $B$, Under current-clamp, the reduction in apamin-sensitive current manifested itself as a reduction in single-spike afterhyperpolarization and as a general depolarization (same cell as in A). Note also the steepening of the voltage trajectory in the interspike interval and the rise in the threshold for action potential generation. C, Application of the selective SK channel agonist EBIO markedly increased the magnitude of current that was evoked by the protocol described in A.D, Current-clamp recording of the same neuron in C. EBIO increased the magnitude and duration of single-spike afterhyperpolarization, which led a reduction in the frequency of autonomous oscillation.

posed of relatively apamin-sensitive subunits (Ishii et al., 1997) and is consistent with the presence of mRNA encoding SK2 $\mathrm{K}_{\mathrm{Ca}}$ and SK3 $\mathrm{K}_{\mathrm{Ca}}$ channels in STN neurons (Stocker and Pedarzani, 2000). 
In some cells, apamin application also further revealed a spike-evoked slowly deactivating inward tail current (Fig. $1 A$ ). In the absence of the slowly deactivating inward tail current, the apamin-sensitive outward current peaked at $6.0 \pm 1.3 \mathrm{msec}$ $(n=8)$ and deactivated with a time constant of $60.2 \pm 6.4 \mathrm{msec}(n=8)$, which were similar to the kinetics of previously reported spike-evoked apamin-sensitive currents (for review, see Sah, 1996; Sah and Faber, 2002).

In current-clamp mode, the blockade of SK $\mathrm{K}_{\mathrm{Ca}}$ channels reduced single-spike afterhyperpolarization and led to a general depolarization (Fig. $1 B$ ). Furthermore, the voltage trajectory associated with the interspike interval was steeper, and the threshold for action potential generation was higher in the presence of apamin (Fig. $1 B$ ).

Although apamin is a widely used selective SK $\mathrm{K}_{\mathrm{Ca}}$ channel antagonist, it does not wash out easily from brain slices, and its effects are typically irreversible. Therefore, to provide further evidence that the effects of apamin were attributable to $\mathrm{SK} \mathrm{K}_{\mathrm{Ca}}$ channel blockade and not run-down in treated neurons, we used EBIO, which selectively enhances the calcium sensitivity

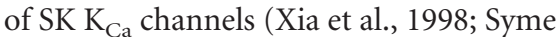
et al., 2000; Pedarzani et al., 2001; Wolfart et al., 2001; Cingolani et al., 2002; Faber and Sah, 2002). We predicted that the effects of SK $K_{\mathrm{Ca}}$ channel activation would be mostly opposite to the effects of SK $\mathrm{K}_{\mathrm{Ca}}$ channel blockade. Under conditions of fast synaptic transmission blockade, bath application of $200 \mu \mathrm{M}$ EBIO increased the mean peak current underlying singlespike afterhyperpolarization by a factor of 1.72 (WSR test; control: $28.2 \pm 4.0 \mathrm{pA}$; EBIO: $48.5 \pm 5.6 \mathrm{pA}, n=7, p=0.018$ )

(Fig. 1C). In current-clamp mode, activation of SK $\mathrm{K}_{\mathrm{Ca}}$ channels with $200 \mu \mathrm{M}$ EBIO markedly increased the afterhyperpolarization that followed autonomously generated action potentials (Fig. 1D).

\section{SK $K_{\mathrm{Ca}}$ channels influence the precision of autonomous} rhythmic single-spike activity in STN neurons

Under perforated recording conditions and in the presence of synaptic transmission blockers, blockade of SK $\mathrm{K}_{\mathrm{Ca}}$ channel current with apamin reduced single-spike afterhyperpolarization and the rhythmicity of autonomous single-spike activity (Fig. 2). The precision of firing was assessed using the coefficient of variation $(\mathrm{CV})$ of 100 interspike intervals of spontaneous activity recorded in current-clamp mode. In accordance with previous studies, STN neurons discharged in a rhythmic single-spike manner in control media (Fig. 2A) (Overton and Greenfield, 1995; Beurrier et al., 1999, 2000; Bevan and Wilson, 1999; Wigmore and Lacey, 2000; Baufreton et al., 2001, 2003; Bevan et al., 2002; Zhu et al., 2002; Do and Bean, 2003) but never exhibited the spontaneous rhythmic burst activity that has been observed by some groups (Beurrier et al., 1999, 2000, 2001; Baufreton et al.,
2001, 2003). The subsequent application of 500 pM apamin reduced single-spike afterhyperpolarization, which increased the rate of activity and decreased the precision of firing (Fig. $2 B$ ). Saturating concentrations of apamin led to a profound reduction of the single-spike afterhyperpolarization, which was accompanied by a further decrease in rhythmicity (Fig. 2C). The apaminsensitivity of periodicity (CV) suggested that the precision of firing was regulated in part by relatively apamin-sensitive SK $\mathrm{K}_{\mathrm{Ca}}$ channels (Fig. 2D). Thus, the mean CV measured in control media $(0.074 \pm 0.005 ; n=27)$ was not significantly different (WSR test) from the mean CV in $10 \mathrm{pM}$ apamin $(0.074 \pm 0.007$; $n=8 ; p=0.8886)$ or the mean CV in $100 \mathrm{pm}$ apamin $(0.08 \pm$ $0.02 ; n=7 ; p=0.2367)$. However, the application of $500 \mathrm{pm}$ apamin resulted in a mean CV that was significantly different from control (WSR test; $0.20 \pm 0.10, n=8, p=0.0173$ ). Further blockade of SK $\mathrm{K}_{\mathrm{Ca}}$ channels produced similar disruptions: the mean CV in $1 \mathrm{nM}$ apamin (WSR test; $0.19 \pm 0.07, n=7, p=$ 0.018 ), the mean CV in $10 \mathrm{~nm}$ apamin (WSR test; $0.20 \pm 0.06, n=$ $5, p=0.0431$ ), and the mean CV in $100 \mathrm{~nm}$ apamin (WSR test; $0.36 \pm 0.09, n=19, p=0.002$ ) were all significantly different from that obtained in control ACSF. Although the mean CV 
A
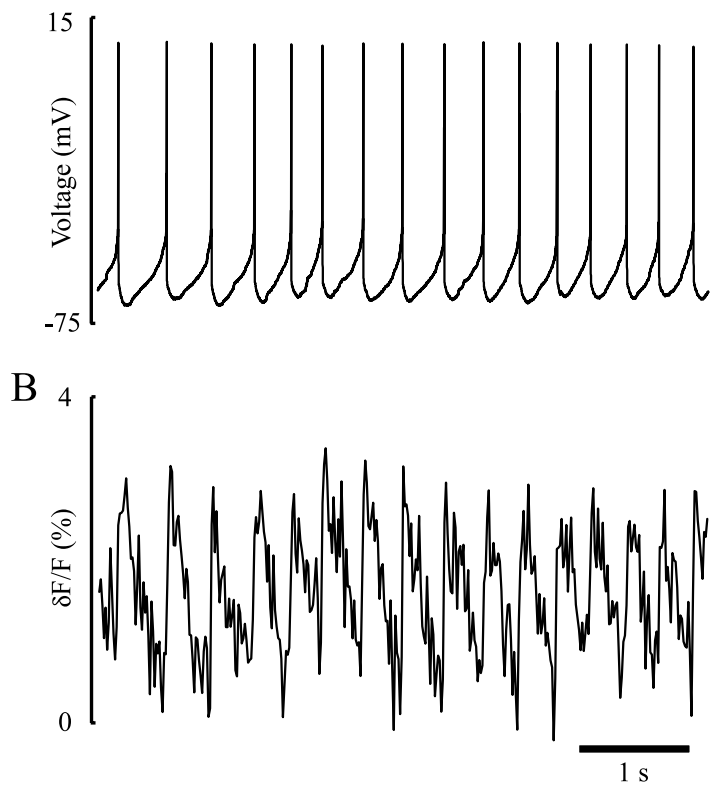

$\mathrm{C}$

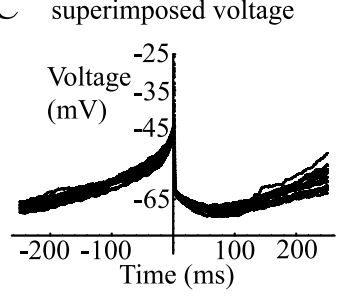

superimposed calcium signal

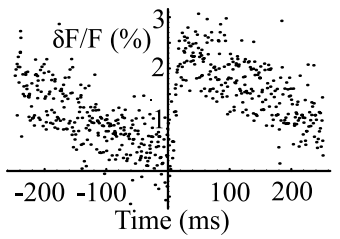

resampled calcium signal $(5 \mathrm{~ms})$

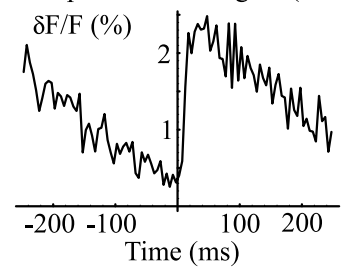

Figure 3. Calcium dynamics faithfully track the autonomous generation of action potentials. $A, B$, Simultaneous electrical $(A)$ and fluorescent $(B)$ recordings from the soma of a spontaneously active STN neuron. Oscillations in membrane potential are phase-locked to oscillations in intracellular calcium levels. C, Using the superimposition of multiple cycles of autonomous activity and related calcium dynamics, more precise temporal resolution of calcium dynamics was achieved (see Results). Calcium levels fell to baseline levels immediately before the generation of an action potential, rose during and after the generation of an action potential, and reached their maximum during the single-spike afterhyperpolarization. Calibration in $B$ also applies to $A$.

appeared to increase at concentrations beyond $1 \mathrm{nM}$, these differences were not significant. The CV in $1 \mathrm{nM}$ apamin was not significantly different from that in $10 \mathrm{nM}(\mathrm{M}-\mathrm{W} U$ test; $n=12, p=$ $0.6847)$ or in $100 \mathrm{~nm}(\mathrm{M}-\mathrm{W} U$ test; $n=12, p=0.0686)$. Thus, the disruption in $\mathrm{CV}$ displayed sensitivity to apamin that was similar to the apamin sensitivity of single-spike afterhyperpolarization that was assessed with the hybrid clamp protocol.

In general, within a cell, the firing rate did not change significantly with apamin application until partial blockade (500 pM) was achieved (Fig. $2 \mathrm{~B}$ ). Firing rate was consistently higher at this concentration (WSR test; control: $12.4 \pm 1.09 \mathrm{~Hz}, n=27 ; 500$ pM: $15.1 \pm 2.6 \mathrm{~Hz}, n=8, p=0.0357)$. Further application of higher concentrations of apamin often led to such profound disruptions in firing pattern and elevation of spike threshold (Figs. $1,2)$ that the mean firing rate was not significantly different from control.

Application of $200 \mu \mathrm{M}$ EBIO did not significantly alter the precision of spontaneous firing in STN cells as measured by the coefficient of variance (WSR test; control: $0.066 \pm 0.007$; EBIO: $0.05 \pm 0.007, n=5, p=0.138$ ), but it did lead to a decrease in the mean firing rate of these cells (WSR test; control: $13.5 \pm 3.0 \mathrm{~Hz}$; EBIO: $8.2 \pm 2.1 \mathrm{~Hz}, n=5, p=0.0422)($ Fig. $1 D)$.

An earlier study suggested that $\mathrm{Ca}_{\mathrm{v}}$ channels contributed to rhythmicity in STN neurons by passing calcium, which in turn activated SK $\mathrm{K}_{\mathrm{Ca}}$ channels (Bevan and Wilson, 1999). These $\mathrm{Ca}_{\mathrm{v}}$ channels appear to be predominantly activated at suprathreshold voltages (Bevan and Wilson, 1999; Song et al., 2000). Indeed, the time course of single spike-evoked SK $\mathrm{K}_{\mathrm{Ca}}$ current, the trajectory of the interspike interval associated with autonomous activity and the effects of apamin on autonomous activity suggest that calcium entry via $\mathrm{Ca}_{\mathrm{v}}$ channels mainly occurs during and subse- quent to action potential generation. To determine directly whether calcium entry during spontaneous activity was primarily associated with the generation of action potentials, we studied calcium dynamics directly using imaging with fura- 2 . The temporal resolution of this method (15-25 msec, depending on the magnitude of the field of view) is typically not adequate to determine whether calcium entry begins just before or during the action potential, nor can it reveal the time to peak of calcium levels. To overcome this limitation, we developed a method for enhancing temporal resolution for repetitive events like rhythmic firing. The method is illustrated for autonomous activity in Figure 3 and is based on the superimposition of data from multiple events. Calcium transients associated with action potentials during spontaneous firing were collected at the highest possible temporal resolution (25 msec in this example). Individual cycles of membrane potential and calcium signal during spontaneous activity were extracted and aligned on the action potential. Because sampling of the calcium signal occurred asynchronously with the action potential, the calcium samples were out of register with each other in the superimposition. Thus, each cycle of the spontaneous activity provided a set of calcium measurements at different times. Assuming that the calcium transient is the same for each action potential (Helmchen et al., 1996), then superimposing the data from different action potentials gives a time series with resolution increased approximately by a factor of the number of superimposed spikes. In the example in Figure 3 and in three other neurons that were studied with this technique, it was apparent that calcium levels in STN neurons did not begin to rise before the action potential and reached their peak during the early phase of the spike afterhyperpolarization. This is consistent with calcium entry via $\mathrm{Ca}_{\mathrm{v}}$ channels with activation and deactivation kinetics slower than those of the action potential currents. The calcium current was activated by the depolarization of the action potential but outlasted the action potential, that is, the calcium current was mostly a tail current of the action potential. If the calcium entering $\mathrm{Ca}_{\mathrm{v}}$ channels is solely responsible for the calcium transient, then the time required for deactivation of the calcium current can be approximated as the time required for the calcium influx to plateau $(\sim 20 \mathrm{msec})$. The time course of calcium decay after the action potential was approximately exponential $(441.2 \pm 217.2 \mathrm{msec} ; n=4)$, and calcium levels returned to approximately baseline levels $(\sim 0 \%)$ before the occurrence of the next action potential in the series. Arresting the spontaneous activity in four of four neurons tested by hyperpolarizing current injection did not produce detectable decreases below background levels of calcium (data not shown). Taken together, our observations suggest that action potential generated calcium dynamics rather than background calcium levels are important for the activation of SK $\mathrm{K}_{\mathrm{Ca}}$ channels in STN neurons.

The decay of intracellular calcium that was measured with imaging was much slower than the decay of SK $\mathrm{K}_{\mathrm{Ca}}$ current mea- 
sured using the hybrid clamp protocol. Similar observations have been made in other neurons and are thought to arise from the fact that the average level of intracellular calcium is not a precise reflection of the calcium concentration that is present in the vicinity of SK $\mathrm{K}_{\mathrm{Ca}}$ channels (Wilson and Callaway, 2000).

\section{SK $K_{\mathrm{Ca}}$ channels influence the sensitivity of STN neurons to depolarizing input}

STN neurons are capable of maintaining high firing rates in response to synaptic input or current injection (Kitai and Deniau, 1981; Rouzaire-Dubois and Scarnati, 1985, 1987; Nakanishi et al., 1987; Fujimoto and Kita, 1993; Mouroux et al., 1995; Bevan and Wilson, 1999). The putative role of SK $\mathrm{K}_{\mathrm{Ca}}$ channels in highfrequency firing was investigated by comparing driven firing in control media and in the presence of apamin (Fig. 4A-D). Neurons were driven for $500 \mathrm{msec}$ from rest with ascending steps of $20 \mathrm{pA}$ of injected current. When the relationship between frequency and current ( $f-I$ relationship) was plotted, STN neurons exhibited a sigmoidal function that was similar to an earlier report that used the whole-cell recording technique (Fig. 4B) (Bevan and Wilson, 1999). The $f-I$ curve was composed of a low-sensitivity primary range up to $\sim 40 \mathrm{~Hz}$, a more sensitive secondary range, and a tertiary range at which the frequency of discharge began to saturate. In control conditions, STN cells fired up to $500 \mathrm{~Hz}$ and displayed, on average, a secondary range to primary range slope ratio of $1.93 \pm 0.14(n=21)$. Partial and saturating blockade of apamin-sensitive current increased the firing rate of STN neurons during periods of applied positive current (Fig. $4 A, B$ ). This manifested itself as both a leftward shift in the secondary range (Fig. $4 \mathrm{Bi}$ ) and as an increase in the gradient of the primary range (Fig. $4 \mathrm{Bii}$ ). The first effect was quantified within each cell as the normalized amount of current needed to achieve the half-maximal firing rate (Fig. $4 C$ ). As illustrated in Figure 4, $A$ and $B i$, and shown for the population in Figure $4 C$, concentrations of $1 \mathrm{nM}$ apamin or greater significantly reduced this amount (WSR test; 10 pM: $1.07 \pm 0.04, n=8, p=0.0747 ; 100$ pM: $1.02 \pm 0.06, n=7, p=0.8658 ; 500$ pM: $0.97 \pm 0.03, n=8$, $p=0.3980 ; 1 \mathrm{nm:} 0.74 \pm 0.05, n=7, p=0.018 ; 10 \mathrm{~nm}: 0.70 \pm$ $0.06, n=6$, p 0.0277; 100 nM: $0.77 \pm 0.04, n=14, p=0.0019)$. In the primary range, partial and saturating blockade of the apaminsensitive current led to an increase in the responsiveness of STN cells to current injection (Fig. $4 A, B, D$ ). Although the normalized slope of the primary range was not significantly changed by the application of $100 \mathrm{pM}$ apamin or less (WSR test; 10 pM: $1.04 \pm$ $0.05, n=8, p=0.5754 ; 100$ pM: $1.00 \pm 0.04, n=6, p=0.9165)$, the application of $500 \mathrm{pm}$ apamin or more led to a significant increase in this gradient (WSR test; 500 pM: $1.22 \pm 0.08, n=6$, $p=0.0277 ; 1 \mathrm{~nm}: 1.58 \pm 0.14, n=7, p=0.018 ; 10 \mathrm{~nm}: 1.86 \pm$ $0.15, n=6, p=0.0277 ; 100 \mathrm{~nm}: 1.68 \pm 0.11, n=13, p=0.0015)$. As complete inhibition of the apamin-sensitive current had no significant effect on the normalized slope of the secondary range in STN neurons ( $100 \mathrm{nm:} 0.98 \pm 0.07, n=13, p=0.4802$ ), the difference between the slopes of the primary and secondary ranges decreased, and a linearization transpired, such that the ratio of the slope of the primary range over the slope of the secondary range was significantly higher as it approached 1 (100 nм: $0.95 \pm 0.07, n=13, p=0.0015)$. Thus, current mediated through apamin-sensitive channels normally acts to limit the excitability of STN neurons and plays a critical role in maintaining the characteristic shape of the $f-I$ relationship. The dosesensitivity of these effects (Fig. 4A-D) is suggestive that they were mediated in large part by channels containing relatively apaminsensitive subunits.
Enhancement of SK $\mathrm{K}_{\mathrm{Ca}}$ channel activity with EBIO produced effects on high-frequency discharge that were opposite to treatment with apamin. Mean firing rates were decreased as compared with control rates in response to equivalent amounts of injected current (Fig. 4E,F). This manifested itself as a rightward shift in the $f-I$ relationship for these cells (Fig. $4 E, F$ ). The normalized amount of current required to achieve the half-maximal firing rate was increased after application of EBIO (WSR test; $1.31 \pm$ $0.04, n=5, p=0.0431)$. Activation of SK $\mathrm{K}_{\mathrm{Ca}}$ channels also led to a decrease in the responsiveness of STN cells to current injection in both the primary and secondary ranges of the $f-I$ relationship (Fig. $4 E, F)$. The normalized slopes of the primary $(0.65 \pm 0.05$; $n=5)$ and secondary ranges $(0.77 \pm 0.07 ; n=5)$ were significantly reduced by EBIO (WSR test; $p=0.0431$ ) (Fig. $4 E, F$ ). In contrast to the linearization observed in the presence of apamin, the relative changes in both slopes were similar in EBIO, such that the ratio of the slope of the primary range to the slope of the secondary range in control media was not altered by application of the drug (WSR test; control: $0.50 \pm 0.06$; EBIO: $0.43 \pm 0.05$, $n=5, p=0.3452$ ) (Fig. 4E,F).

\section{SK $\mathrm{K}_{\mathrm{Ca}}$ channels do not determine intratrain spike-frequency dynamics in STN neurons}

Although SK $\mathrm{K}_{\mathrm{Ca}}$ channels dictated the overall sensitivity of STN neurons to depolarizing input, they did not control firing dynamics within periods of driven firing (Fig. 5). At firing rates in the secondary and tertiary range of the $f-I$ curve, STN neurons displayed an initial increase in firing rate when driven (Fig. $5 B-D$ ). At all levels of driven firing, STN neurons also displayed a subsequent minor but consistent spike-frequency adaptation (Fig. 5). Both of these properties were unchanged by the application of saturating concentrations of apamin in seven of seven neurons tested. Furthermore, comparison of interval and instantaneous frequency plots from driven firing of similar frequencies under control conditions and in the presence of apamin revealed that intratrain spike-frequency dynamics were virtually identical $(n=$ 7). Similarly, spike-frequency dynamics during periods of driven firing were relatively unchanged after activation of these channels with $200 \mu \mathrm{M}$ EBIO (Fig. $4 E, F$ ). When traces of similar mean frequency were compared, EBIO did not increase spikefrequency adaptation. Taken together these data suggest that intratrain spike-frequency dynamics are primarily controlled by channels other than SK $\mathrm{K}_{\mathrm{Ca}}$ channels.

\section{SK $\mathrm{K}_{\mathrm{Ca}}$ channels, in part, underlie post-train afterhyperpolarization in STN neurons}

High-frequency firing also led to an accumulation in the depth and duration of post-train apamin-sensitive afterhyperpolarization in STN neurons (Fig. 6). Thus, the interval between a period of high-frequency firing and the resumption of spontaneous firing increased as a function of both the current used to drive the cell and the mean frequency realized during the driven period (Fig. 6A, $C, D, F, G, I)$. Under control conditions, the time to the first spike after driven firing was approximately linearly related to the mean frequency of driven activity (Fig. $6 A, C, D, F, G, I$ ). Across 14 cells examined, the mean slope of this relationship was $3.28 \pm$ $0.67 \mathrm{msec} / \mathrm{Hz}$. Saturating concentrations of apamin widely abolished the post-train afterhyperpolarization but had one of two opposite effects on the resumption of spontaneous activity. Complete blockade of SK $\mathrm{K}_{\mathrm{Ca}}$ channels with saturating concentrations of the drug prolonged the time to the first spike after driven firing in 6 of 15 neurons examined (Fig. $6 A-C$ ). In five neurons, blockade of the $\mathrm{SK} \mathrm{K}_{\mathrm{Ca}}$ channels led to a shortening of the interval 
A
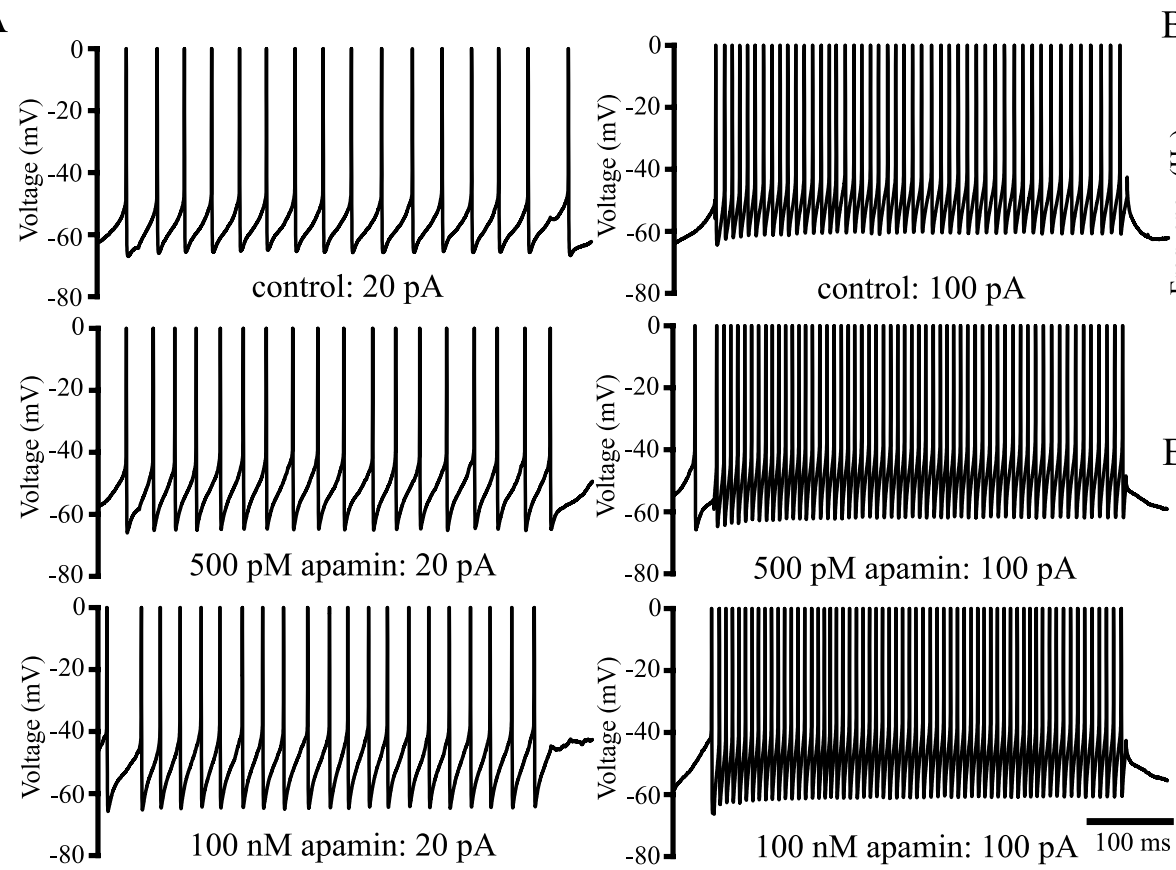

$\mathrm{B}(\mathrm{i})$

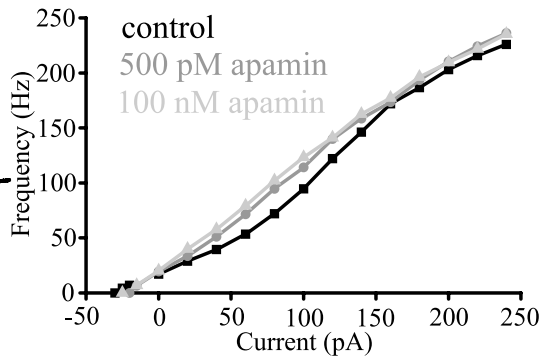

B(ii)

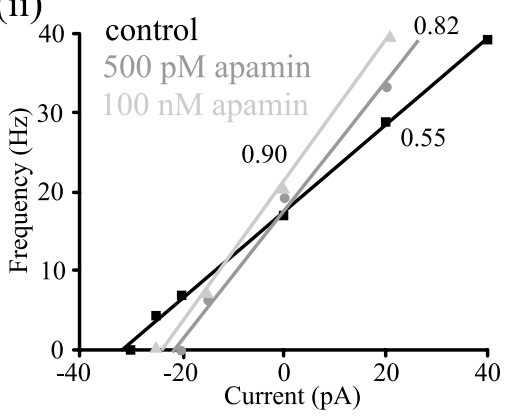

$\mathrm{C}$

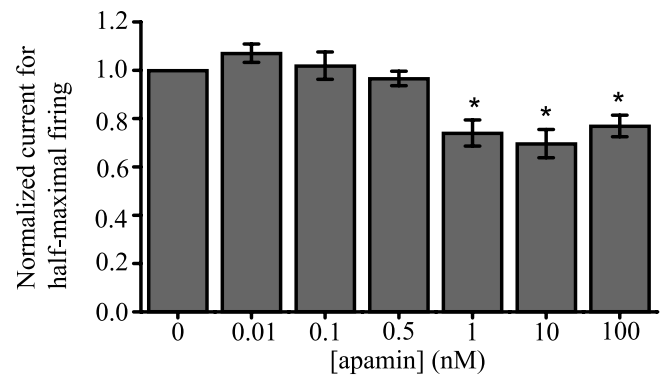

$\mathrm{D}$

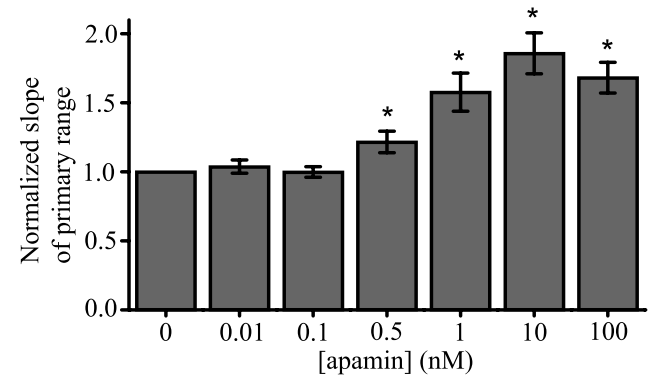

$\mathrm{E}$
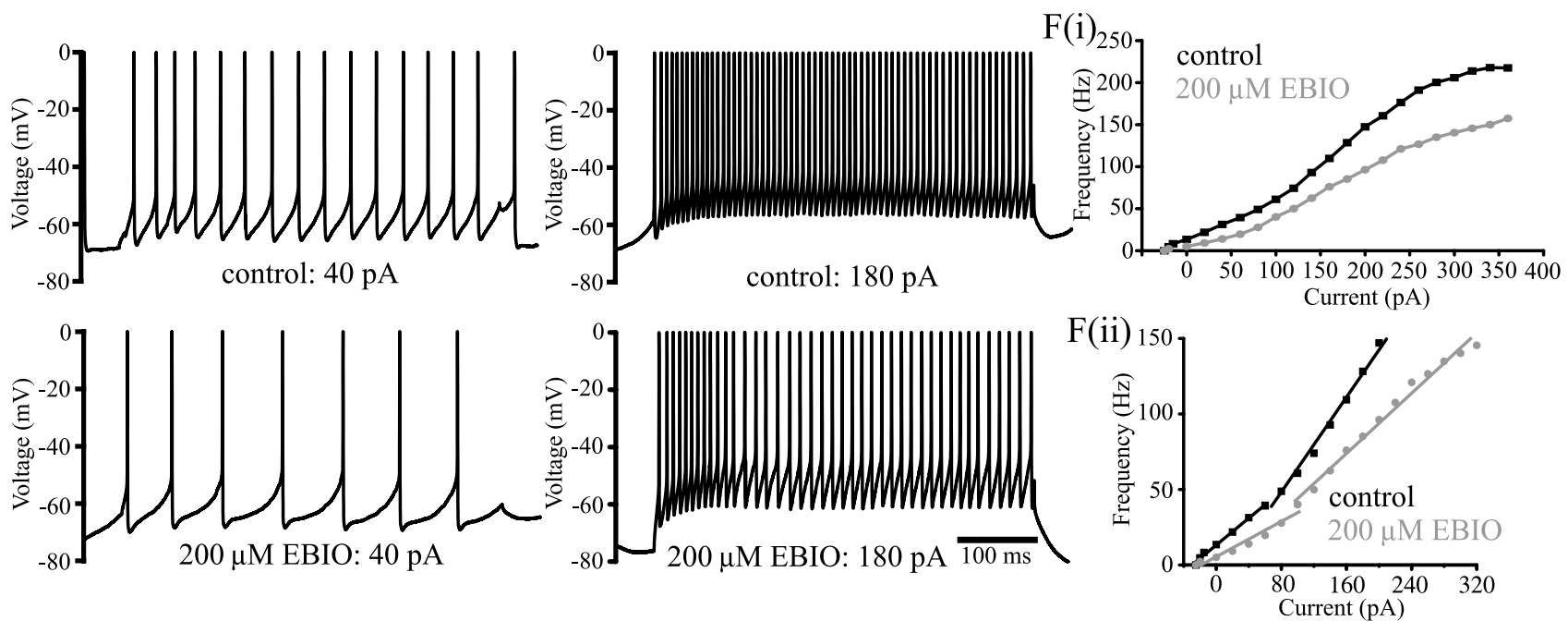

Figure 4. SKK $\mathrm{Ca}_{\mathrm{a}}$ channels influence the sensitivity of firing to depolarizing input. $A-D$, Driven firing was augmented in a dose-dependent manner by the application of apamin. Apamin increased the frequency of firing in response to current injection in both the primary and secondary firing ranges. The $f-I$ relationship was shifted leftwards $(B i, C)$ and the gradient of the primary range $(B, D)$ resembled that of the secondary range. Thus, apamin at concentrations $>500$ and $100 \mathrm{pm}$ significantly decreased the current required for half-maximal firing ( $C$ ) and increased the gradient of the primary range ( $D$ ), respectively. E, F, Driven firing was markedly reduced by the application of EBIO. Fi, The $f-I$ relationship of the neuron in $E$ was shifted right by EBIO. Fii, The gradients of primary and secondary range firing were reduced by $S K \mathrm{~K}_{\mathrm{Ca}}$ channel activation, but the ratio of the sensitivities of primary to secondary range firing were unaltered.

between the termination of driven firing and the first subsequent action potential (Fig. $6 D-F$ ). In the remaining four cells, apamin treatment produced such great variability in the resumption of spontaneous activity that a clear pattern was not observed. These mixed responses indicate that $\mathrm{SK} \mathrm{K}_{\mathrm{Ca}}$ channels are important for the smooth and uniform resumption of spontaneous activity after high-frequency activity in STN neurons. In the absence of SK $\mathrm{K}_{\mathrm{Ca}}$ channels, the resumption of activity is less uniform, across the population and within individual neurons. The involvement of SK $\mathrm{K}_{\mathrm{Ca}}$ channels in post-train afterhyperpolarization was con- 
firmed by the application of $200 \mu \mathrm{M} \mathrm{EBIO}$, which increased the post-train afterhyperpolarization and the time for the resumption of firing after driven firing in five of five neurons (Fig. $6 G-I$ ).

\section{The role of SK $\mathrm{K}_{\mathrm{Ca}}$ channels during repeated cycles of high-frequency activity}

The build-up of post-train afterhyperpolarization has been suggested as one possible mechanism that might underlie the therapeutic value of high-frequency stimulation of the STN for the treatment of PD (Bevan and Wilson, 1999; Dostrovsky and Lozano, 2002). To test this proposition further, we drove cycles of high-frequency activity in STN neurons with repeated injections of current in control conditions and in the presence of apamin (Fig. 7). In agreement with the data described above, apamin treatment produced faster firing on each cycle of current injection, reduced post-train afterhyperpolarization between cycles of current injection, but had no effect on the decline in spiking during successive cycles of activity (Fig. 7). These data suggest that during cycles of highfrequency activity there will be a build-up of spike-generated afterhyperpolarization, which will reduce activity between cycles of current injection. In addition, a second apamin-insensitive process leads to a gradual reduction in firing during repeated cycles of current injection. The accommodation and broadening of action potentials during successive cycles of activity suggest that the slow inactivation of $\mathrm{Na}_{\mathrm{v}}$ channels may be responsible (Do and Bean, 2003).
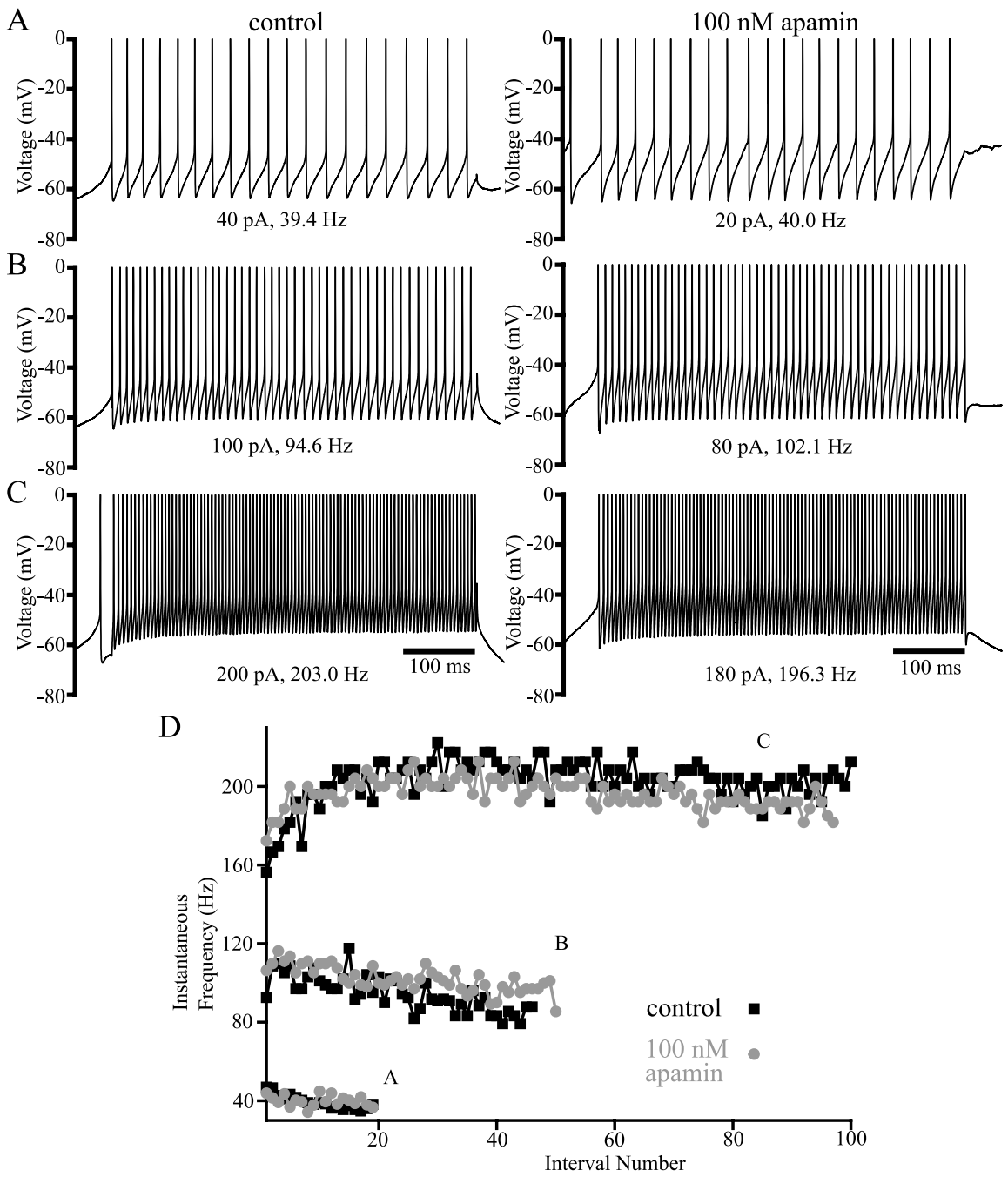

Figure 5. Intratrain spike-frequency dynamics are not controlled by SK $\mathrm{K}_{\mathrm{Ca}}$ channels. $A-D$, Comparison of firing of similar frequency in control conditions and in the presence of apamin revealed that the pattern of spiking within a driven train was not altered by apamin. The speed-up in firing, which was followed by minor spike-frequency adaptation at high frequencies of activity was present in control conditions and in the presence of apamin. Calibration in Calso applies to $A$ and $B$.

\section{Intracellular calcium accumulates}

\section{during and decays slowly after driven repetitive firing}

The slow decay of intracellular calcium during autonomous activity, the slow decay of single spike-evoked apamin-sensitive SK $\mathrm{K}_{\mathrm{Ca}}$ channel current, and the accumulation of post-train apaminsensitive afterhyperpolarization suggested that during highfrequency repetitive activity intracellular calcium accumulates and leads to the persistent activation of $\mathrm{SK} \mathrm{K}_{\mathrm{Ca}}$ channels. Combined calcium imaging with fura-2 and electrical recording were used to directly test this hypothesis (Fig. 8). Spontaneous activity was arrested during these experiments by the constant injection of hyperpolarizing current to maintain a baseline level of intracellular calcium. These experiments confirmed that intracellular calcium accumulated and did not return to baseline levels during repetitive firing of frequencies greater than $\sim 10 \mathrm{~Hz}$. Furthermore, the accumulation of intracellular calcium was dependent on the frequency of action potential generation during $1 \mathrm{sec}$ periods of driven activity. After each period of driven firing, calcium levels gradually fell to baseline levels over a period of several seconds. A linear relationship was observed between the peak calcium level and frequencies of driven activity $>10 \mathrm{~Hz}$ (Fig. 8). Similar relationships for action potential generation and calcium fluorescence were observed in each of 10 neurons tested.
SK $\mathrm{K}_{\mathrm{Ca}}$ channels preferentially determine the duration and intensity of rebound activity in STN neurons with shortduration rebound bursts

Using previously published criteria (Bevan et al., 2000, 2002), the majority of STN neurons generated a rebound burst of activity in response to the removal of a 500-msec-long period of hyperpolarizing current injection $(n=23 / 30 ; 77 \%)$. Based on the findings of Bevan et al. (2002), rebound burst responses were scrutinized in neurons in which the membrane potential was driven to a peak hyperpolarization of $-79.0 \pm 3 \mathrm{mV}$ because this represents a potential of key physiological significance, the mean equilibrium potential of GABA-A IPSPs in STN neurons. In this study, 52\% of neurons $(n=12 / 23)$ displayed burst rebound responses at peak hyperpolarizations in this range. Using the classifications outlined in Bevan et al. (2002), 58\% of these cells fired bursts of $<100$ msec in duration $(n=7 / 12$; mean duration $=33.7 \pm 9.5 \mathrm{msec})$, and $42 \%$ fired bursts with durations $>100 \mathrm{msec}(n=5 / 12$; mean duration $=310.9 \pm 130.1 \mathrm{msec}$ ). These mixed responses imply heterogeneity in the intrinsic burst-generating mechanisms of STN neurons. Thus, burst responses were compared after the application of apamin to assess whether this heterogeneity could be accounted for by differences in apamin-sensitive current (Fig. 

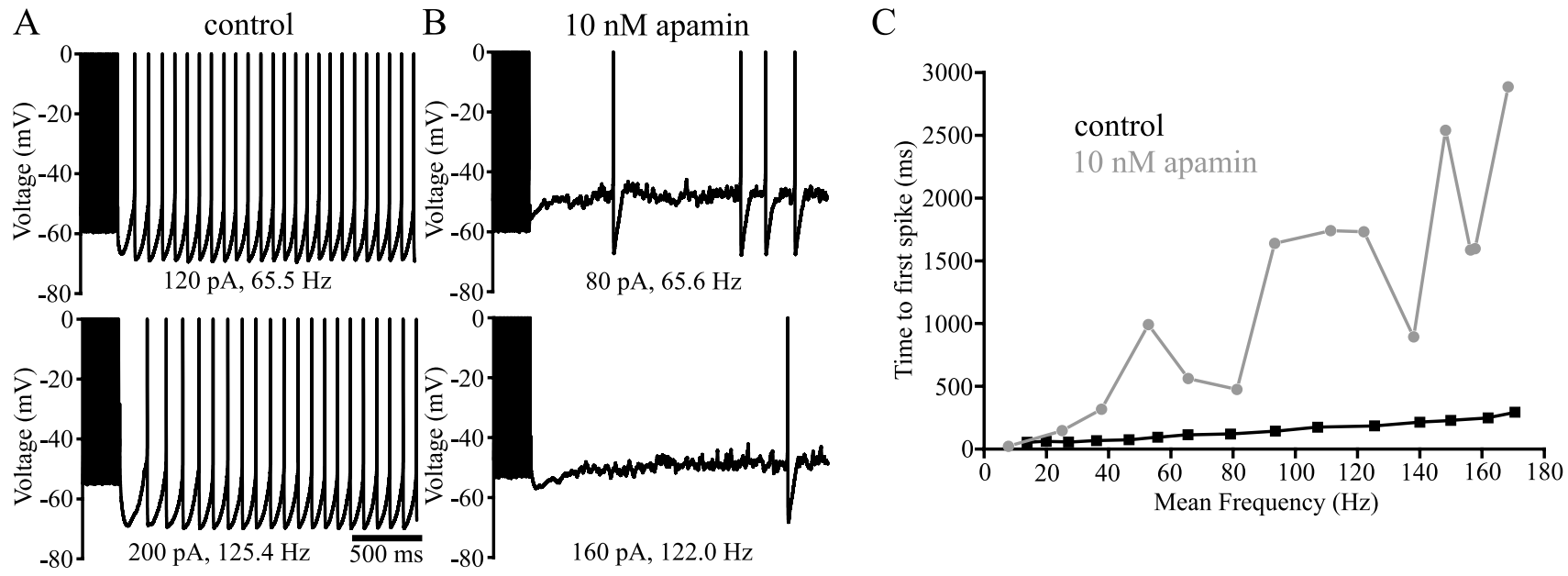

F
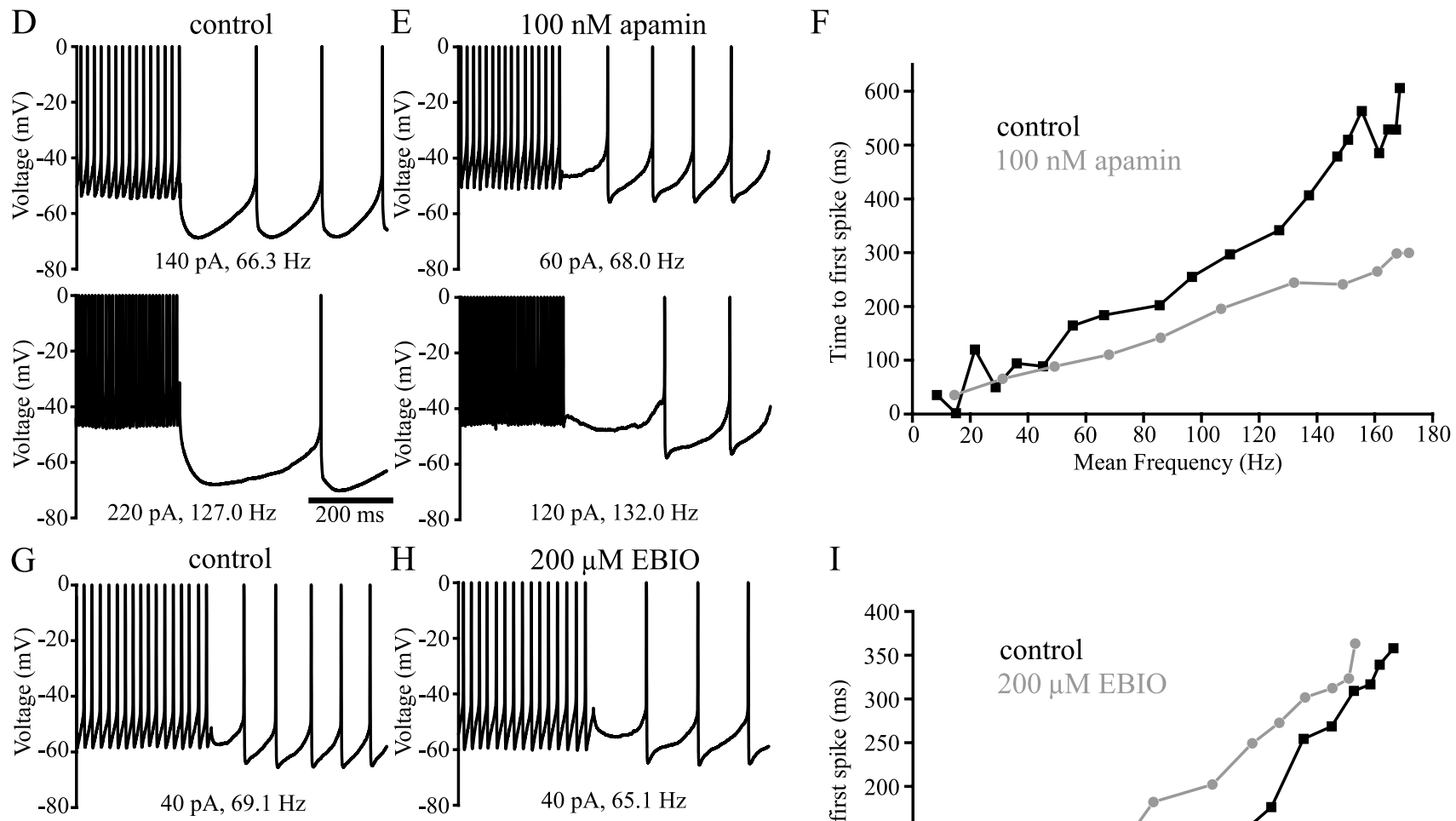

$\mathrm{H} \quad 200 \mu \mathrm{M}$ EBIO
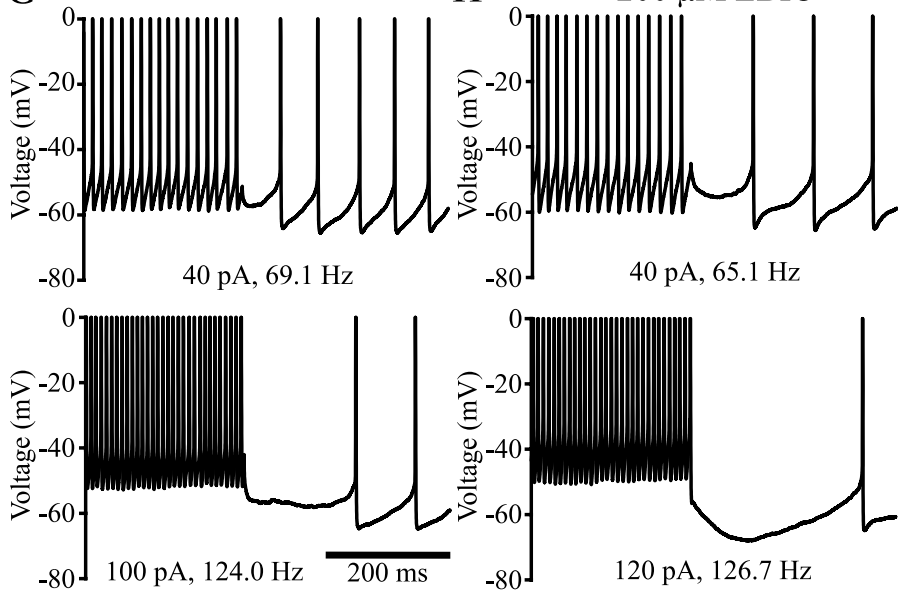

I

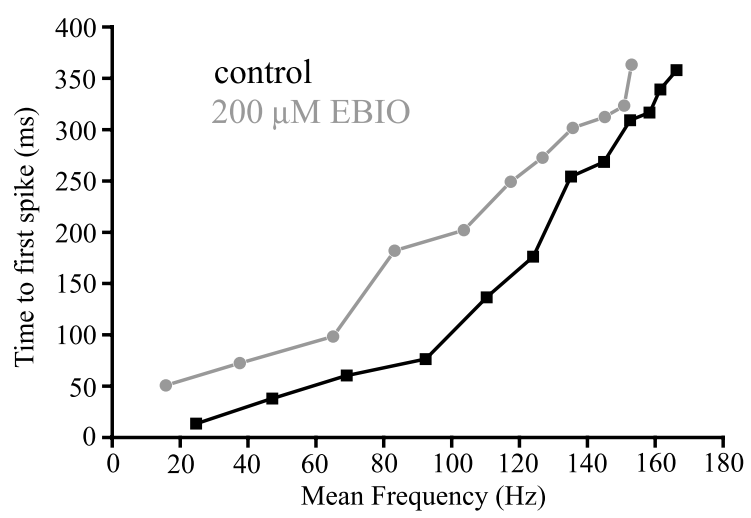

Figure 6. SK $\mathrm{K}_{\mathrm{Ca}}$ channels in part underlie post-train afterhyperpolarization. $A-l$, High-frequency firing led to the accumulation of post-train apamin-sensitive afterhyperpolarization, which delayed the resumption of spontaneous activity. $A-F$, Post-train afterhyperpolarization was reliably reduced in duration and magnitude by the application of apamin. The abolition of apaminsensitive post-train afterhyperpolarization either increased $(A-C)$ or reduced $(C-E)$ the time for the resumption of spontaneous activity. Thus, in the absence of $S K K_{C a}$ channel activation, the manner in which spontaneous activity resumes after high-frequency activity is more heterogeneous. G-I, EBIO consistently increased the magnitude and duration of post-train afterhyperpolarization and the time for the resumption of spontaneous activity. Calibration in $A$ also applies to $B$. Calibration in $D$ also applies to $E$. Calibration in $G$ also applies to $H$.

9). The mean duration of burst responses elicited from peak hyperpolarizations of $-79.0 \pm 3 \mathrm{mV}$ was increased 10 -fold for the entire population of short-duration burst response neurons (mean duration $=304.1 \pm 119.2 ; n=7 ; p=0.018$ ) (Fig. 9A). Whereas the mean burst duration for all neurons with burst responses longer than $100 \mathrm{msec}$ was also significantly higher in saturating apamin (mean duration $=466.0 \pm 140.5 ; n=5 ; p=$ 0.0431 ) (Fig. $9 B$ ), the relative increase in duration was much smaller in these neurons. Indeed, the mean fold-increase in burst duration after apamin application was significantly higher for neurons with rebound durations $<100 \mathrm{msec}$ (M-W $U$ test; duration $<100$ msec: mean fold-increase $=9.23 \pm 3.1, n=7$; dura- 

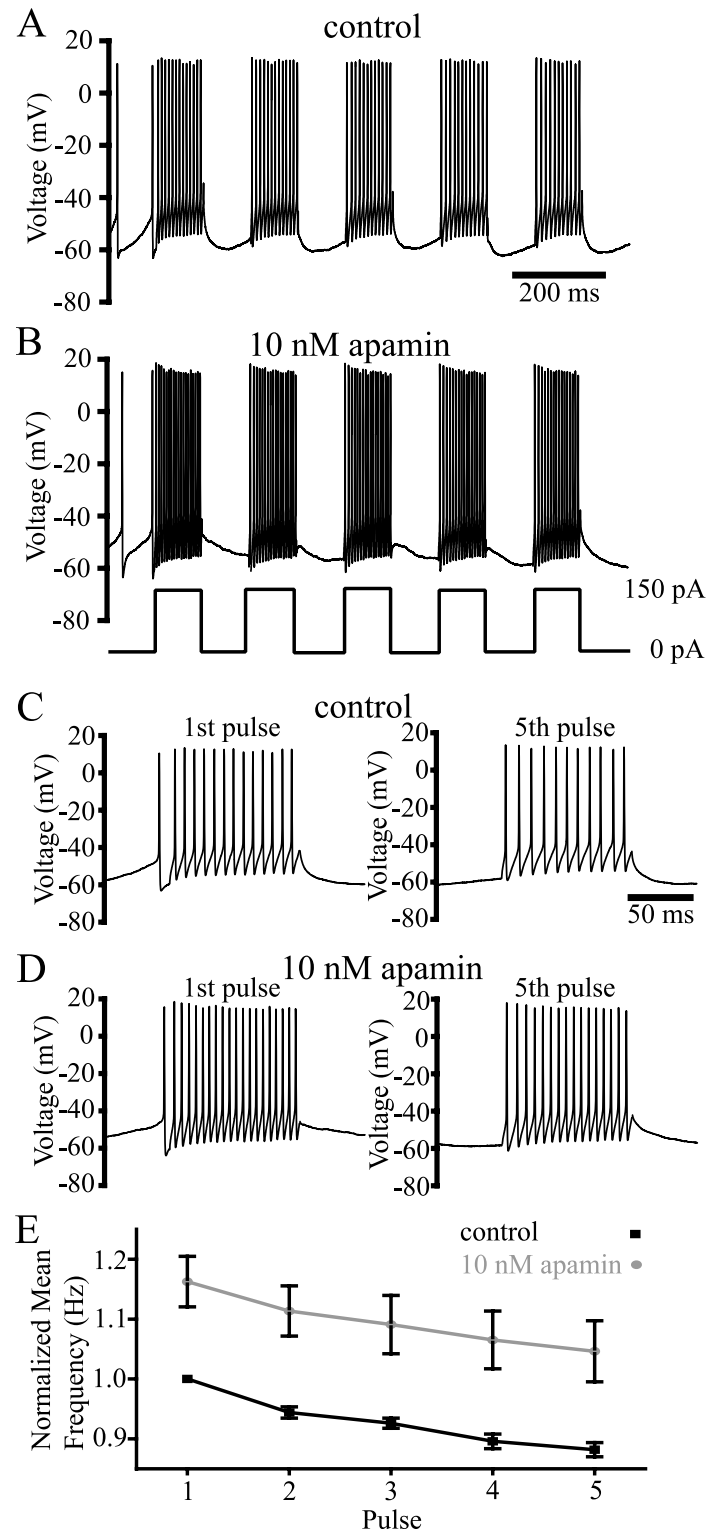

Figure 7. $S_{K} K_{C a}$ channels underlie the build-up of post-train afterhyperpolarization but do not underlie the reduction in intratrain spike frequency during successive cycles of driven activity. A-E, An STN neuron was driven with repeated cycles of current injection: $150 \mathrm{pA}$ for 100 $\mathrm{msec}$, which was repeated five times with an interval of $100 \mathrm{msec}$. The post-train afterhyperpolarization, which increased during successive cycles of activity $(A)$ was apamin-sensitive $(B)$. The successive decline in intratrain firing was, however, apamin-insensitive and was associated with the marked accommodation and broadening of action potentials $(A-E)$. Calibration in $A$ also applies to B. Calibration in Calso applies to D.

tion $>100$ msec: mean fold-increase $=1.71 \pm 0.2, n=5 ; p=$ $0.028)$. SK $K_{\mathrm{Ca}}$ channels therefore strongly curtailed burst duration in one subpopulation of STN neurons (short-duration rebounding cells) but were less influential in another subpopulation (long-duration rebounding cells). It might be hypothesized that long-duration rebounding cells simply express fewer SK $\mathrm{K}_{\mathrm{Ca}}$ channels, which exert a minor influence on rebound responses. However, the size of the apamin-sensitive single-spike afterhyperpolarization (as measured in voltage-clamp mode as per Fig. 1) was not significantly different in neurons with short-duration or long-duration rebound bursts $(\mathrm{M}-\mathrm{W} U$ test; short-duration = $55.6 \pm 6.9 \mathrm{pA}$; long-duration $99.0 \pm 31.3 \mathrm{pA} ; p=0.5637)$. Similarly, the effects of SK $K_{\mathrm{Ca}}$ channel blockade on autonomous
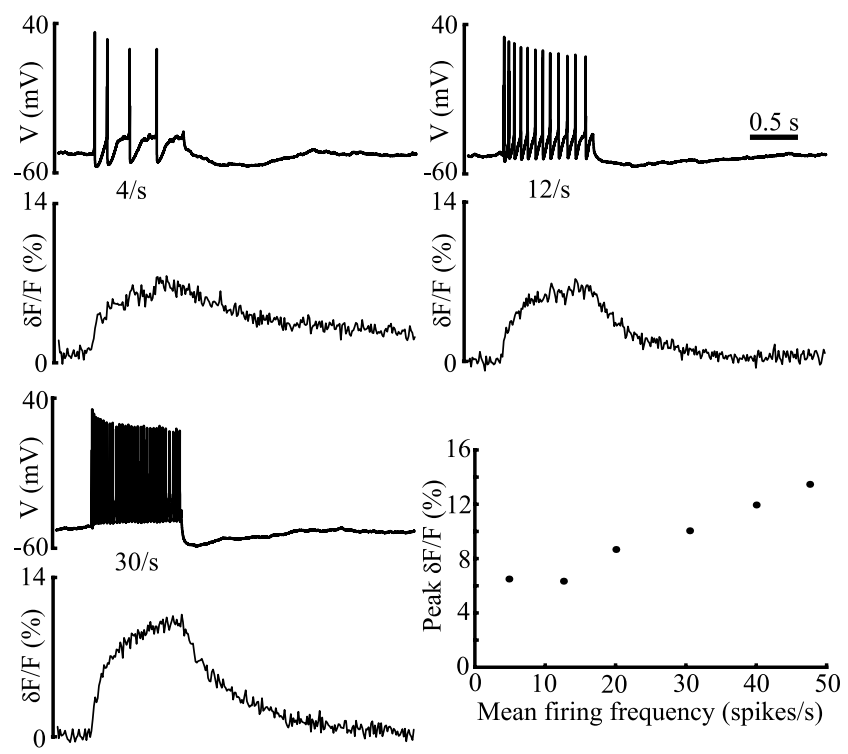

Figure 8. Intracellular calcium levels accumulate during driven repetitive activity. Combined electrical and fluorescent measurements indicated that intracellular calcium accumulated when repetitive firing was driven at frequencies of $>10 \mathrm{~Hz}$. Intracellular calcium did not return to baseline levels during repetitive firing but did return slowly to baseline levels after driven firing over a period of several seconds. There was a linear relationship between the number of action potentials generated by current injection and the peak level of intracellular calcium for firing frequencies $>10 \mathrm{~Hz}$.

activity (M-W $U$ test; short-duration: $\mathrm{CV}=0.39 \pm 0.14, n=7$; long duration: $\mathrm{CV}=0.27 \pm 0.12 n=4 ; p=0.3447)$ and driven firing (M-W $U$ test; short duration: normalized current for half maximal firing $=0.75 \pm 0.069, n=3$; long duration: normalized current for half maximal firing $=0.84 \pm 0.10, n=7, p=0.4759$ ) were similar in neurons with short- and long-duration rebound bursts.

The capability of SK channels to control rebound activity in STN neurons was confirmed by the application of $200 \mu \mathrm{M}$ EBIO, which strongly truncated rebound burst responses (Fig. 9C). When comparing population data for responses elicited with peak hyperpolarizations in the -76 to $-82 \mathrm{mV}$ range, burst duration was significantly shortened by EBIO (WSR test; control: $230.8 \pm 97.7 \mathrm{msec}$; EBIO: $61.7 \pm 33.4 \mathrm{msec}, n=5, p=0.0431$ ). In summary, $\mathrm{SK} \mathrm{K}_{\mathrm{Ca}}$ channels therefore play a critical role in determining the nature of rebound activity, but factors that determine their activation during rebound activity but not autonomous or driven activity are heterogeneous.

\section{Rebound responses are associated with action potential- independent calcium entry}

The heterogeneous effects of SK $\mathrm{K}_{\mathrm{Ca}}$ channels blockade on rebound bursting, but not other forms of activity, suggest that calcium dynamics during rebound activity are different from those associated with autonomous or driven activity. During autonomous and driven activity, the majority of calcium entry was associated with action potentials. We hypothesized that during rebound activity there is likely to be an additional recruitment of $\mathrm{Ca}_{\mathrm{v}}$ channels that activate below spike threshold. By adjusting the holding potential or the degree of hyperpolarization produced during 500-1000 msec hyperpolarizing current injections, rebound responses that were below the threshold for action potential generation were generated. Under these conditions, we clearly observed that calcium entry was associated with the early and late phases of subthreshold rebound responses in each of 

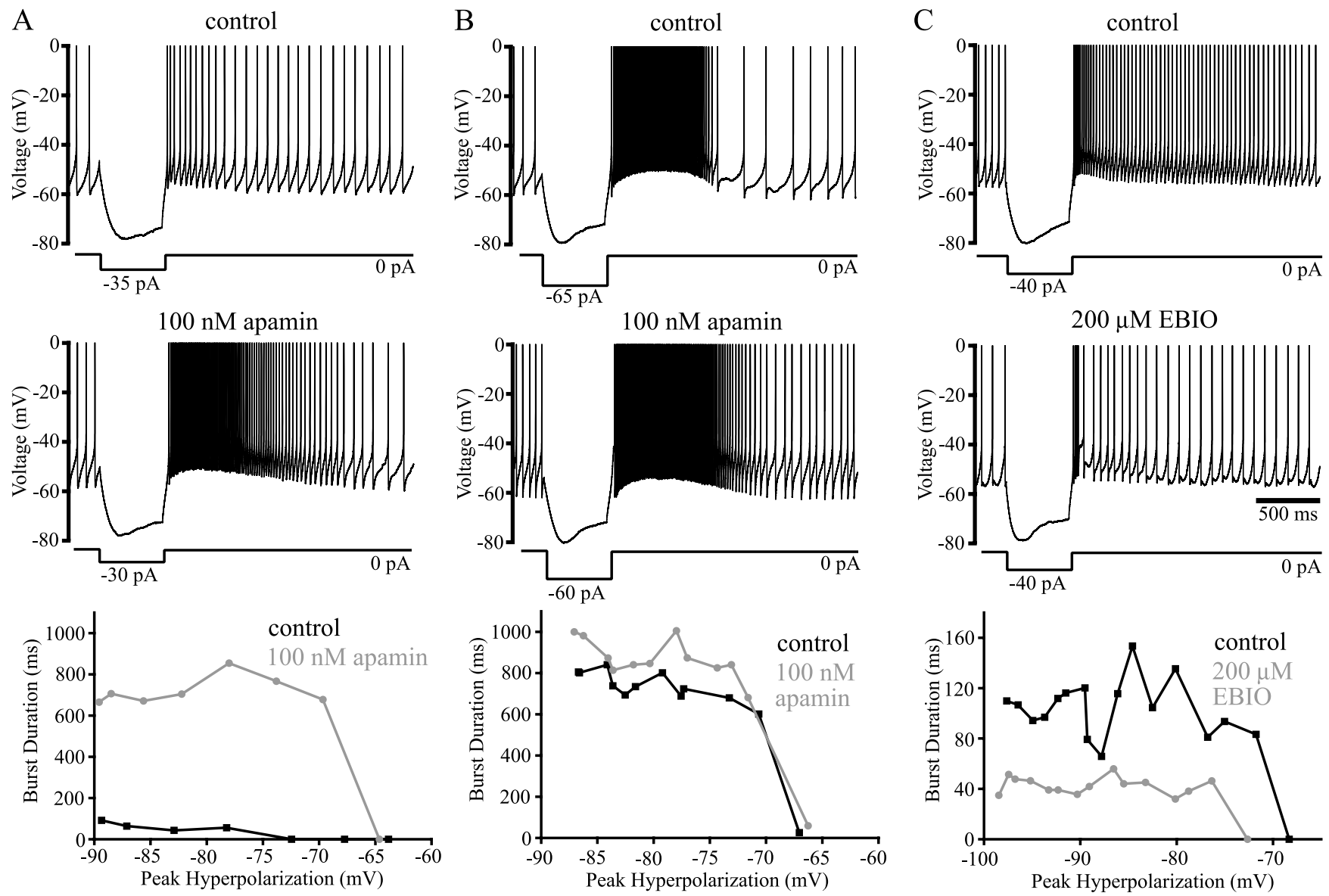

Figure 9. SK K $\mathrm{Ca}_{\mathrm{Ca}}$ channels differentially sculpt rebound activity in neurons with short- and long-duration rebound bursts. $A$, The application of $100 \mathrm{~nm}$ apamin to a neuron with a rebound burst response of $<100$ msec extended greatly the duration and intensity of rebound activity at all levels of preceding hyperpolarization. $B$, In contrast, more modest effects on rebound activity were observed when $100 \mathrm{~nm}$ apamin was applied to a neuron with a long-duration rebound burst response ( $>500 \mathrm{msec}$ ) in control conditions. C, Application of EBI0 consistently shortened the duration of rebound bursts evoked after hyperpolarization to a range of membrane potentials. Calibration in $C$ also applies to $A$ and $B$.

seven neurons that were examined (Fig. 10). These and previous findings (Beurrier et al., 1999, 2000; Bevan and Wilson, 1999; Song et al., 2000; Otsuka et al., 2001; Bevan et al., 2002; Baufreton et al., 2003) point to the involvement of $\mathrm{Ca}_{\mathrm{v}}$ channels in the underlying rebound depolarization. These channels recover from inactivation when hyperpolarized below the potentials associated with autonomous oscillation and driven firing and are strongly activated at subthreshold voltages. The early component of the rebound depolarization has been shown previously to be mediated, in part, by $\mathrm{Ca}_{\mathrm{v}}$ channels that inactivate rapidly, are highly nickel-sensitive, and are therefore presumably derived from the $\mathrm{Ca}_{\mathrm{v}} 3$ class (Beurrier et al., 1999, 2000; Song et al., 2000; Otsuka et al., 2001). The long-lasting component of the rebound depolarization appears to be mediated in part by slowly inactivating/ noninactivating, nifedipine-sensitive $\mathrm{Ca}_{\mathrm{v}} 1.2-1.3$ channels (Beurrier et al., 1999; Otsuka et al., 2001). The calcium imaging presented here confirms that calcium entry is indeed associated with the early and late phases of subthreshold rebound depolarization (Fig. 10).

\section{SK $K_{\mathrm{Ca}}$ channels are critical determinants of the pattern of} rhythmic activities in STN neurons

Spontaneous bursting activity in STN neurons has been observed occasionally (Beurrier et al., 1999, 2000, 2001; Baufreton et al., 2001, 2003). When it has been observed, gluconate was used as the intracellular anion, and/or GABA-A receptors were concur- rently blocked with the methiodide salt of bicuculline. In recent years it has been shown that both the intracellular application of gluconate and the extracellular application of bicuculline methiodide block SK $\mathrm{K}_{\mathrm{Ca}}$ channels and SK $\mathrm{K}_{\mathrm{Ca}}$ channel-mediated functions (Zhang et al., 1994; Johnson and Seutin, 1997; Seutin et al., 1997; Velumian et al., 1997; Debarbieux et al., 1998; Aizenman and Linden, 1999; Stocker et al., 1999). We therefore tested whether rhythmic burst activity could be induced in neurons recorded in the perforated configuration by the application of apamin. In these and all other slice experiments in this study, we used antagonists of fast synaptic transmission that are not known to block SK $\mathrm{K}_{\mathrm{Ca}}$ channels. Rhythmic burst activity in STN neurons has been most commonly generated by the injection of negative holding current and hyperpolarization to voltages not normally associated with spontaneous oscillation (Beurrier et al., 1999, 2000, 2001; Baufreton et al., 2001, 2003). Thus, we applied tonic hyperpolarizing current in an attempt to induce this form of activity. In the perforated patch recordings reported here and previously (Bevan et al., 2000, 2002), spontaneous burst activity was never observed in control conditions either at rest or when the membrane was hyperpolarized with negative current (Fig. $11 A)$. In contrast, after the application of apamin, burst activity was induced by equivalent levels of hyperpolarizing current in 5 of $8(63 \%)$ STN neurons (Fig. $11 B)$. This activity was quantified using the CV of the distribution of 120 interspike intervals and the Lomb periodogram of the autocorrelation of 121 spikes. For 


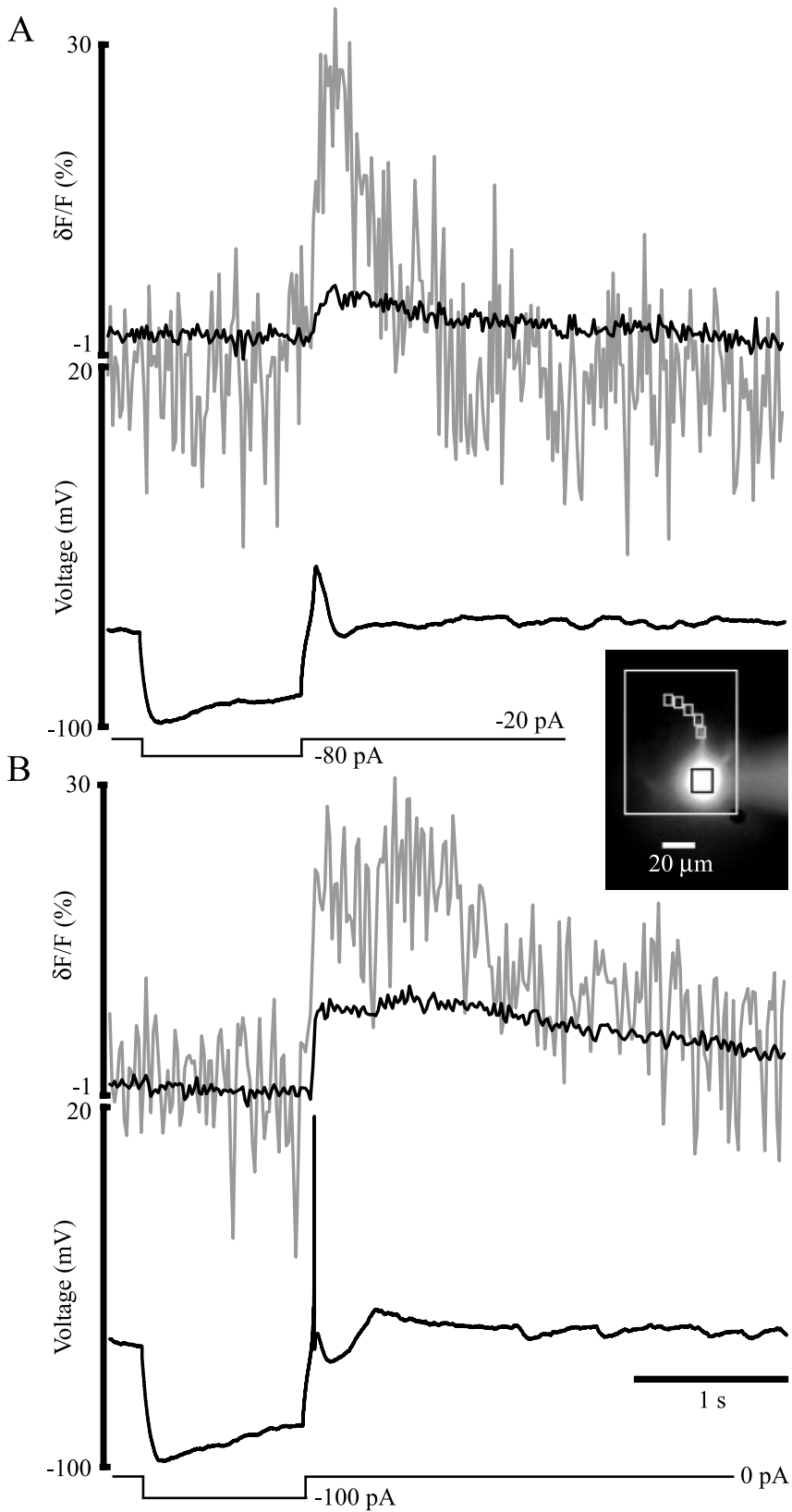

Figure 10. Action potential-independent calcium entry during rebound activity. $A, B, C o m-$ bined fluorescent and electrical recordings subthreshold and suprathreshold rebound responses in an STN neuron (inset). $A$, After the termination of a hyperpolarizing current step, a low-threshold calcium spike was generated without accompanying action potentials. The calcium spike was associated with a marked increase in intracellular calcium in both the soma (black trace) and dendrites (gray trace). $B$, In the same neuron, the early phase of a suprathreshold rebound response was followed by a later and longer lasting subthreshold response that was also associated with an increase in calcium in the soma and dendrites of the STN neuron. Calibration in $B$ also applies to $A$.

the five neurons that developed burst activity, their mean CV measures increased significantly (WSR test; control: $0.25 \pm 0.02$; $10 \mathrm{~nm}$ apamin: $2.1 \pm 0.40, n=5, p=0.0431$ ), and the interspike interval histograms constructed from data in the presence of apamin displayed counts at long interval times that were not apparent in the interspike interval histograms constructed using control data. In addition, the predominant frequencies of activity identified by Lomb periodograms indicated a shift in control conditions from a frequency $(7.06 \pm 2.7 \mathrm{~Hz})$ that was close to the
A

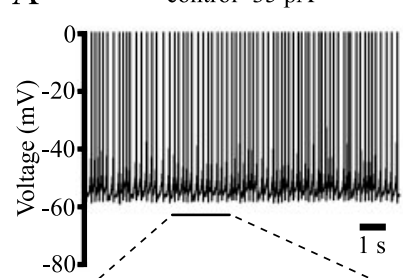

B $\quad 100 \mathrm{nM}$ apamin $-35 \mathrm{pA}$
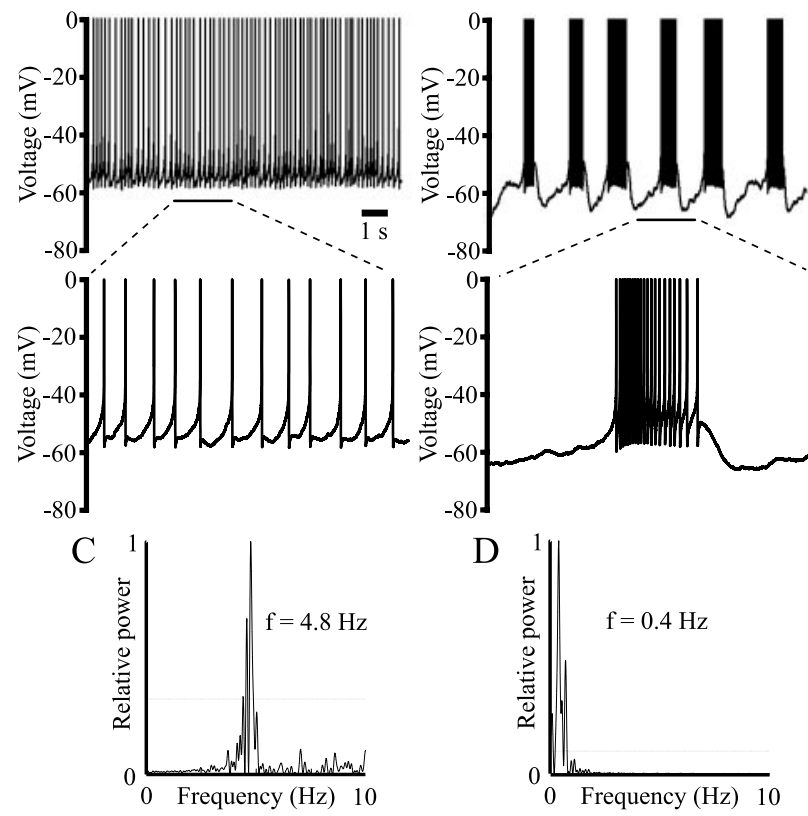

Figure 11. SKK $\mathrm{K}_{\mathrm{Ca}}$ channel blockade and hyperpolarization transform rhythmic single-spike activity into rhythmic burst activity. $A, B$, Tonic, slow, rhythmic single-spike activity $(A)$ was transformed into tonic, rhythmic burst activity when $\mathrm{SK} \mathrm{K}_{\mathrm{C}_{\mathrm{a}}}$ channels were blocked $(B) . C, D$, Note also that after $S_{K} K_{C a}$ channel blockade, the predominant frequency in the Lomb periodogram switched from a frequency that was similar to the mean frequency of single-spike activity $(C)$ to a frequency that was similar to the frequency at which bursts occurred $(D)$. The horizontal line in the Lomb periodograms denotes a level of significance of $p=0.05$. Calibration in $A$ also applies to $B$.

mean frequency of single-spike activity $(4.54 \pm 0.91)$ to a frequency $(0.75 \pm 0.1 \mathrm{~Hz})$ that was dissimilar to the mean frequency of activity $(6.4 \mathrm{~Hz} \pm 1.39)$ but matched the frequency of burst activity in apamin (Fig. 11). These data indicate that rhythmic low-frequency burst activity can be induced in STN neurons by concurrent $\mathrm{SK} \mathrm{K}_{\mathrm{Ca}}$ channel blockade and somatic hyperpolarizing current injection.

\section{$\mathrm{Ca}_{\mathrm{v}} 2.2$ channels but not $\mathrm{Ca}_{\mathrm{v}} 1.2-1.3$ channels are strongly coupled to $\mathrm{SK} \mathrm{K}_{\mathrm{Ca}}$ channels. $\mathrm{Ca}_{\mathrm{v}} 1.2-1.3$ channels underlie, in part, secondary range firing and long-duration rebound activity}

On the basis of the previous data and the observation that the major contributors of high voltage-activated calcium current in STN neurons are $\mathrm{Ca}_{\mathrm{v}} 2.2$ channels (52\%, Song et al., 2000), we hypothesized that these channels are strongly coupled to SK $\mathrm{K}_{\mathrm{Ca}}$ channels. Using similar analytical and current injection protocols to those described above, we therefore compared autonomous, driven, and rebound activity in neurons under control conditions and in the presence of the selective $\mathrm{Ca}_{\mathrm{v}} 2.2$ channel antagonist $\omega$-conotoxin GVIA $(1 \mu \mathrm{M})$. The effects on autonomous activity and driven activity were similar to the effects of apamin. Thus, $\mathrm{Ca}_{\mathrm{v}} 2.2$ channel blockade reduced the magnitude of single-spike afterhyperpolarization in all 21 neurons tested, reduced the rhythmicity of autonomous activity (WSR test; CV in control media $=0.074 \pm 0.007 ; \mathrm{CV}$ in $\omega$-conotoxin GVIA $=0.165 \pm$ $0.035, n=21, p<0.0001$ ) (Fig. 12A,B), reduced the normalized current to reach half maximal firing (WSR test, $0.88 \pm 0.5, n=$ $20, p=0.0064)$ (Fig. 12D), and increased the normalized gradient of the primary range (WSR test; $1.56 \pm 0.11, n=19, p=$ 0.0005 ) (Fig. 12C,D). In contrast to the effects of SK $\mathrm{K}_{\mathrm{Ca}}$ channel 
A

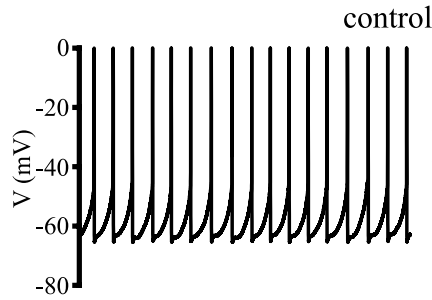

$\mathrm{C}$

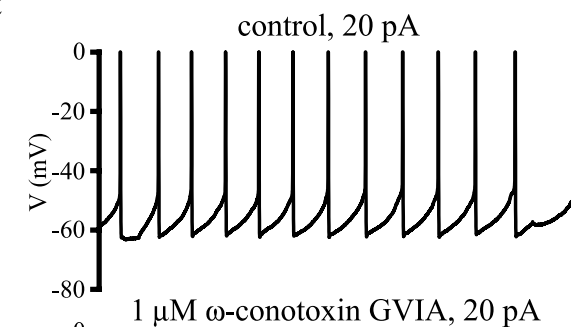

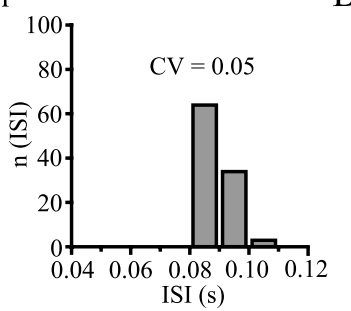

ISI (s)
B

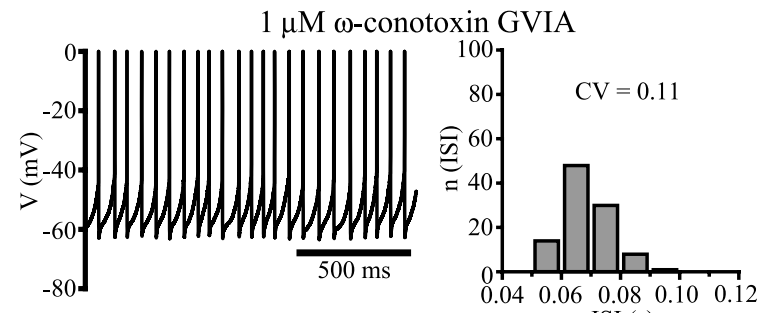

$\mathrm{D}(\mathrm{i})$
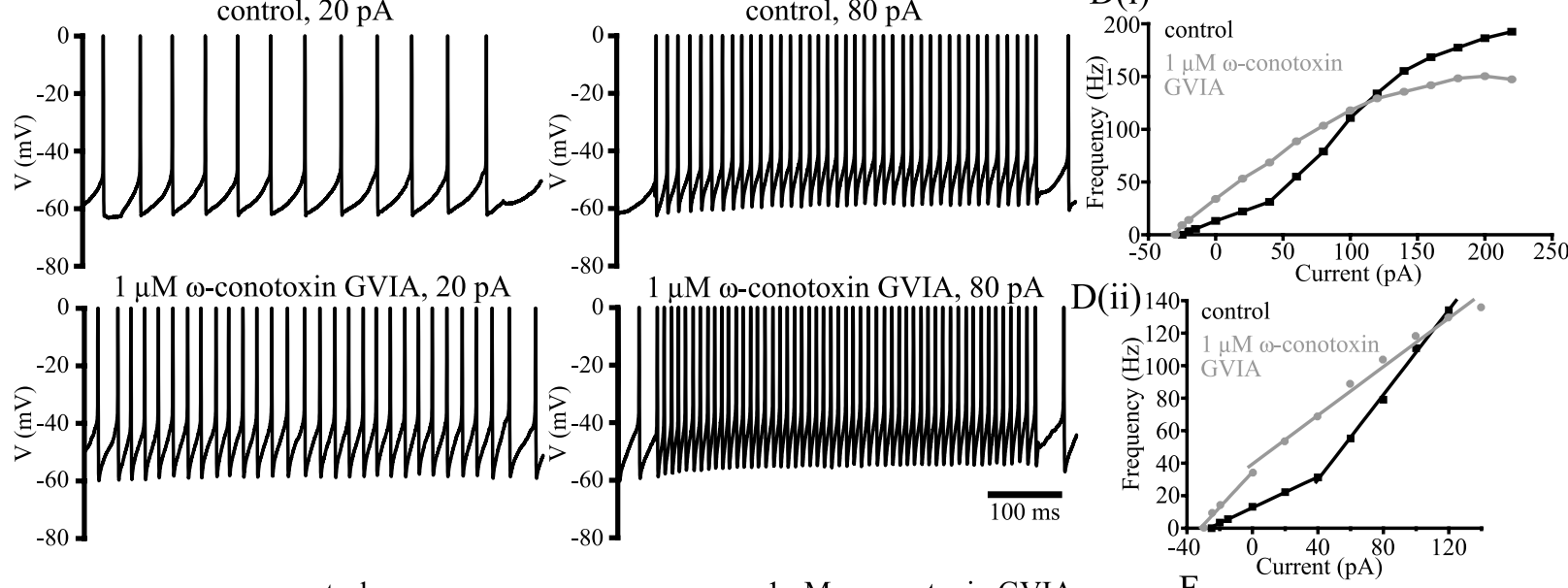

$\mathrm{E}$
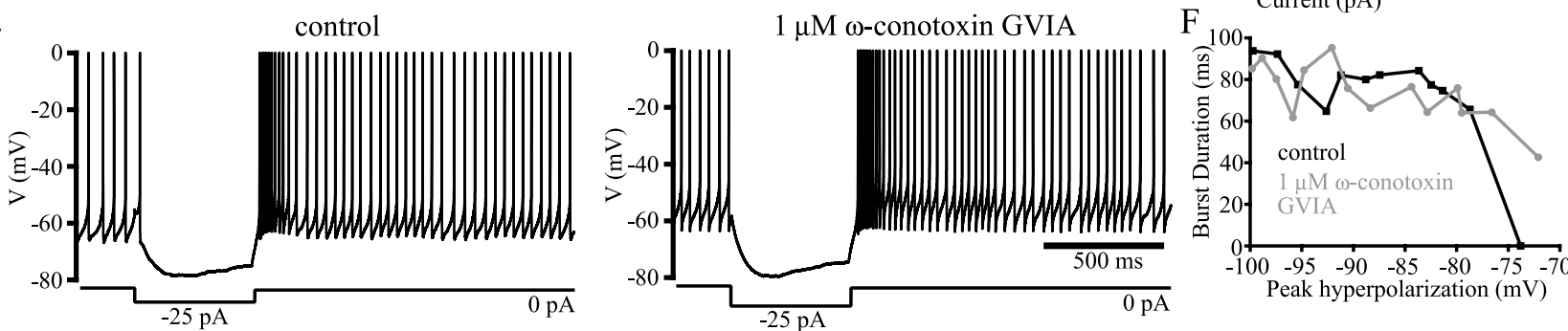

Figure 12. SK K $C_{C}$ channels are strongly coupled to $C_{v} 2.2$ channels. $A, B$, Rhythmic autonomous oscillation and single-spike afterhyperpolarization were disrupted by the application of $\omega$-conotoxin GVIA in a manner that was similar to the effects of apamin. $C, D, \mathrm{Ca}_{\mathrm{v}} 2.2$ channel blockade also increased the frequency of firing in response to current injection, except for the highest frequencies of activity. The gradient of the primary range of the $f-I$ relationship was increased (Di, Dii). Although secondary range firing was generally enhanced by $\mathrm{Ca}_{\mathrm{v}} 2.2$ channel blockade, the gradient of the secondary range of the $f-/$ relationship was decreased $(D i, D i i)$. E, F, In clear contrast to the effects of $S K K_{C_{a}}$ channel blockade, the duration of rebound activity was not altered by $C_{\mathrm{v}} 2.2$ channel blockade. Calibration in $B$ also applies to $A$.

blockade, $\mathrm{Ca}_{\mathrm{v}} 2.2$ channel blockade also reduced the maximal firing frequency (Fig. 12C,D). These data indicate that $\mathrm{Ca}_{\mathrm{v}} 2.2$ channels, in addition to activating SK $\mathrm{K}_{\mathrm{Ca}}$ channels, also contribute a significant inward current that augments high-frequency activity. The effects of $\omega$-conotoxin GVIA on autonomous activity (M-W U test; short-duration: $\mathrm{CV}=0.107 \pm 0.007, n=9$; longduration: $\mathrm{CV}=0.147 \pm 0.020, n=6 ; p=0.099)$, driven highfrequency activity (M-W $U$ test; short duration: normalized current for half maximal firing $=0.96 \pm 0.065, n=9$; long-duration: normalized current for half maximal firing $=0.83 \pm 0.12, n=5$; $p=0.317)$, and primary range activity ( $\mathrm{M}-\mathrm{W} U$ test; shortduration: normalized slope of the primary range $=1.41 \pm 0.13$, $n=9$; long-duration: normalized slope of the primary range $=$ $1.71 \pm 0.33, n=4 ; p=0.2801$ ) were similar in neurons with short-or long-duration rebounds. Interestingly, the duration of rebound activity was not increased by $\mathrm{Ca}_{\mathrm{v}} 2.2$ channel blockade in neurons with short-duration rebounds (WSR test; control $=$ $36.1 \pm 5.9 \mathrm{msec} ; \omega$-conotoxin GVIA $=41.0 \pm 9.6 \mathrm{msec} ; n=9$; $p=0.594$ ) or long-duration rebounds (WSR test; control = $348.95 \pm 109.5 \mathrm{msec} ; \omega$-conotoxin GVIA $=295.02 \pm 107.89$ msec; $n=6 ; p=0.4631$ ), a clear difference to the effects of apamin, which suggests another source of calcium must activate
SK $\mathrm{K}_{\mathrm{Ca}}$ channels during rebound activity (Fig. 12E). Taken together these data suggest that differential coupling of SK $\mathrm{K}_{\mathrm{Ca}}$ channels to $\mathrm{Ca}_{\mathrm{v}} 2.2$ channels is unlikely to account for diversity of rebound activity in STN neurons.

$\mathrm{Ca}_{\mathrm{v}} 1.2-1.3$ channels are the second largest contributors of high-voltage activated calcium current in STN neurons $(21 \%$, Song et al., 2000). Because blockade of $\mathrm{Ca}_{\mathrm{v}} 1.2 .-1.3$ channels with nifedipine has previously been shown to reduce the duration of rebound activity in gluconate and $\mathrm{KCl}$ based whole-cell recording studies of STN neurons, we hypothesized that $\mathrm{Ca}_{\mathrm{v}} 1.2-1.3$ channels might be more weakly coupled to SK $\mathrm{K}_{\mathrm{Ca}}$ channels than $\mathrm{Ca}_{\mathrm{v}} 2.2$ channels in STN neurons. However, coupling of $\mathrm{Ca}_{\mathrm{v}}$ channels to $\mathrm{SK} \mathrm{K}_{\mathrm{Ca}}$ channels may have been disrupted in those whole-cell recording studies for the reasons described above. Comparison of autonomous, driven high-frequency, and rebound activity of STN neurons, in control media and in the presence of the selective $\mathrm{Ca}_{\mathrm{v}} 1.2-1.3$ channel antagonist nifedipine $(5 \mu \mathrm{M})$, confirmed coupling of these channels to SK $\mathrm{K}_{\mathrm{Ca}}$ channels is weak (Fig. 13). Thus, the single-spike afterhyperpolarization associated with autonomous activity was not appreciably altered by nifedipine application in 15 neurons that were challenged, although a slight but significant decrease in rhythmicity was ob- 
A

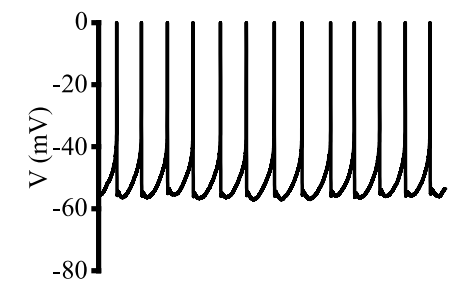

control

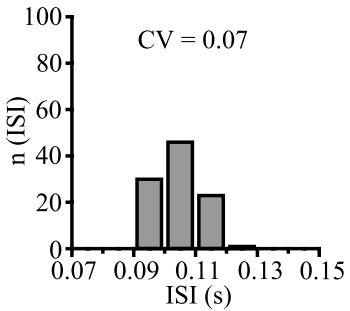

B

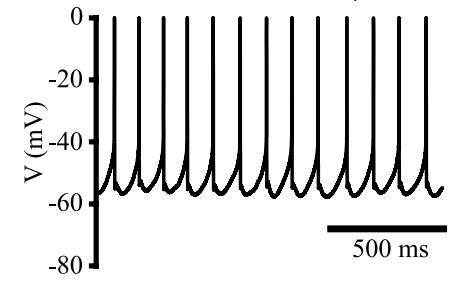

$5 \mu \mathrm{M}$ nifedipine

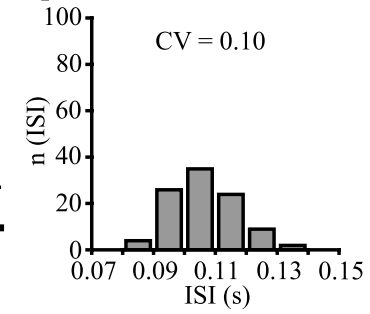

$\mathrm{C}$
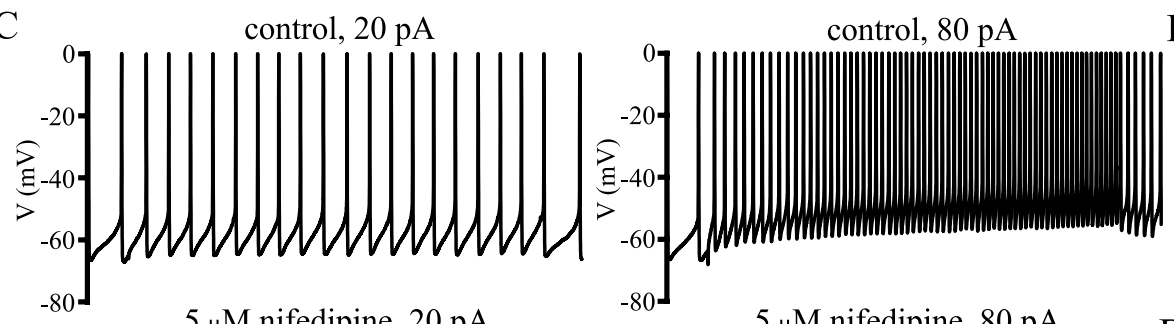

D (i)
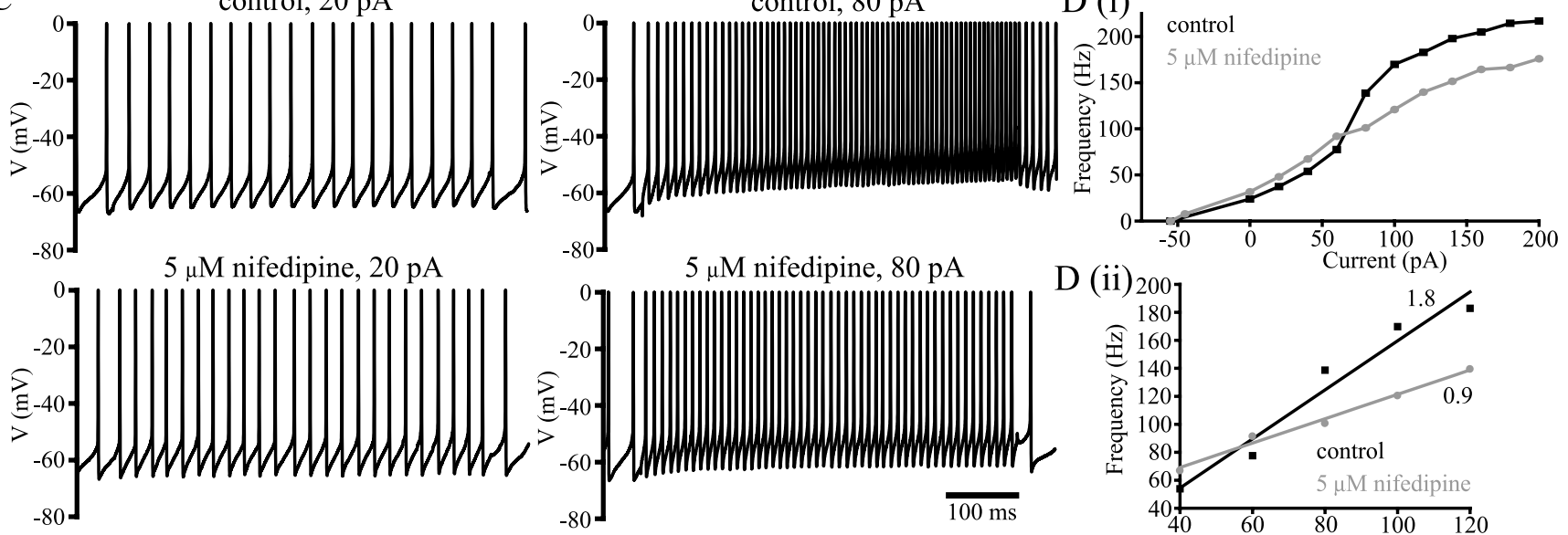

$5 \mu \mathrm{M}$ nifedipine, $80 \mathrm{pA}$

$\mathrm{D}$ (ii) 200
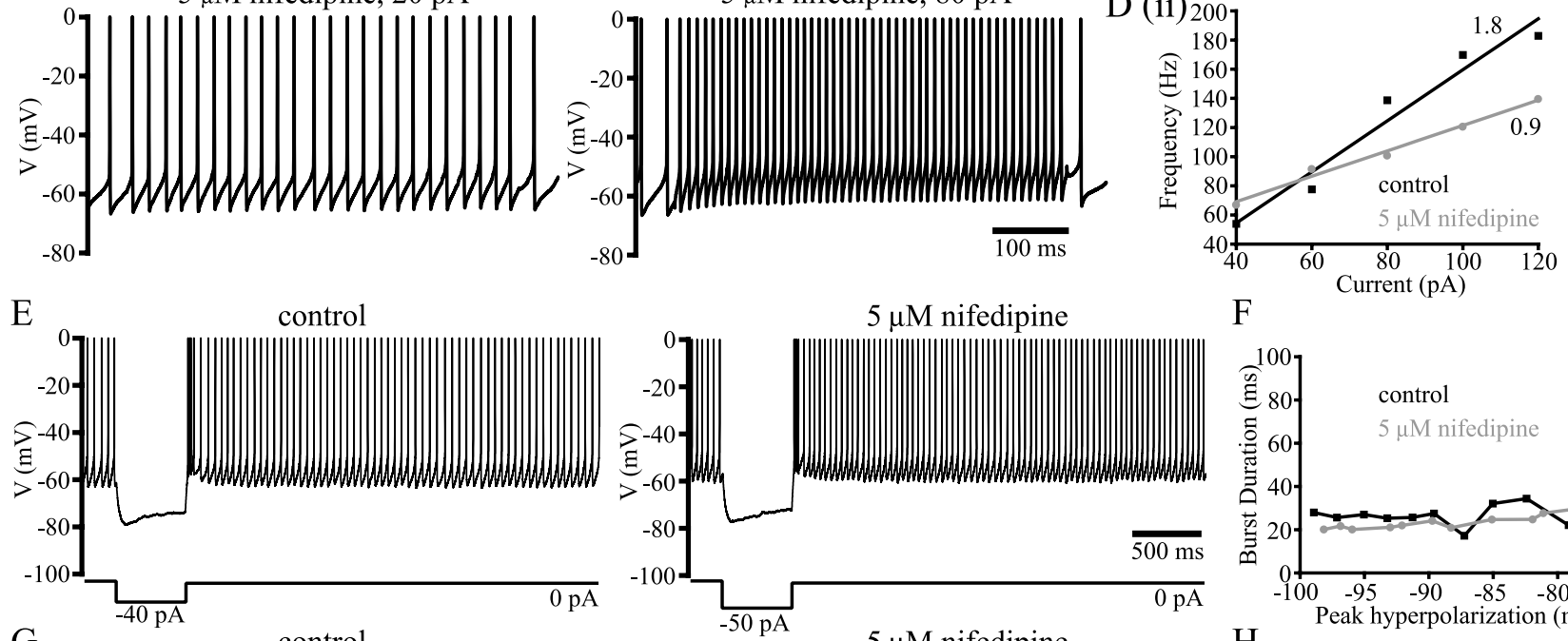

$\mathrm{F}$
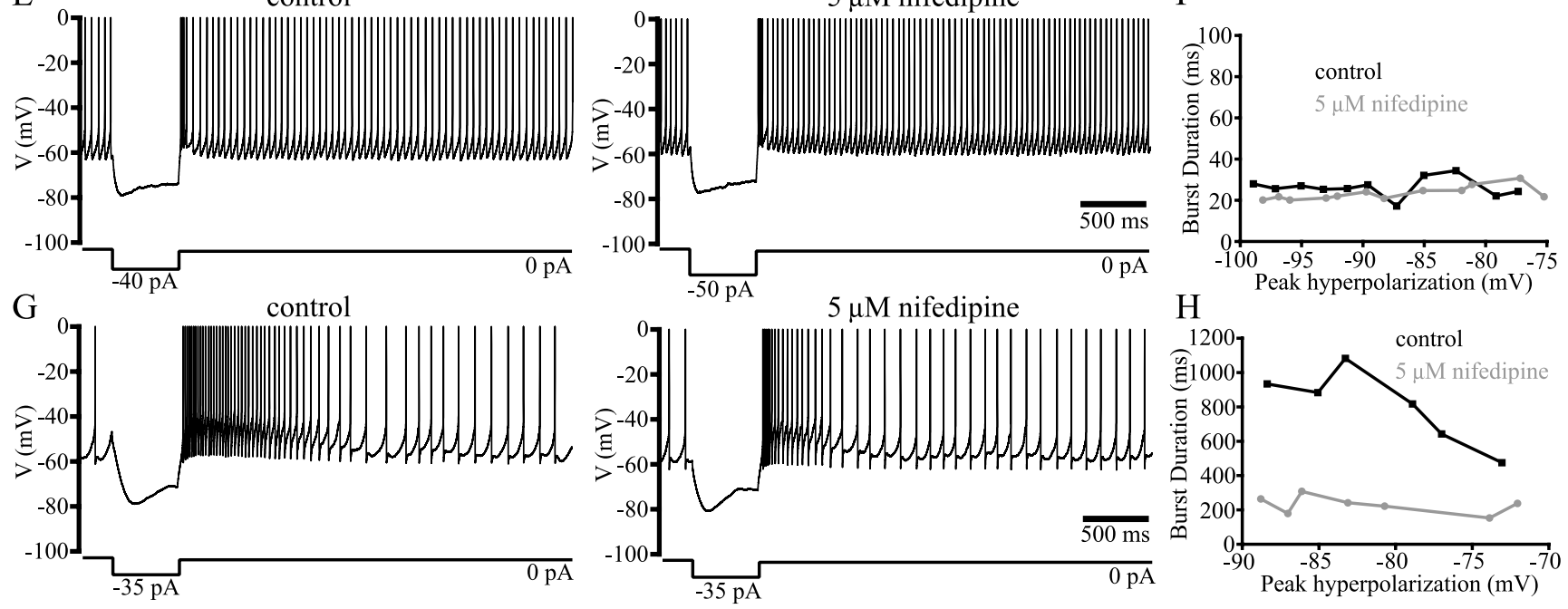

Figure 13. $\quad \mathrm{Ca}_{\mathrm{v}} 1.2-1.3$ channels are weakly coupled to $\mathrm{SKK}_{\mathrm{Ca}}$ channels and contribute to secondary range and long-duration rebound burst firing. $A, B, B$ lockade of $C \mathrm{a}_{\mathrm{v}} 1.2-1.3$ channels produced a slight disruption in the precision of autonomous single-spike activity without a clear effect on single-spike afterhyperpolarization. $C, D, B$ lockade of $C_{v} 1.2-1.3$ channels had little effect on primary range firing but clearly reduced the frequency of secondary range firing and the gradient of the secondary range of the $f-I$ relationship. $E-H$, Blockade of $C a_{v} 1.2-1.3$ channels had no effect on short-duration rebound activity $(E, F)$ but significantly reduced the duration of long-duration rebound activity $(G, H)$. Calibration in $B$ also applies to $A$.

served (WSR test; CV in control $0.069 \pm 0.006$; CV in nifedipine $=0.081 \pm 0.009, n=15, p=0.0409)($ Fig. 13A,B). This was clearly less profound than that after treatment with apamin or $\omega$-conotoxin GVIA and may be a reflection of weak coupling to SK $\mathrm{K}_{\mathrm{Ca}}$ channels and/or a reduced contribution of $\mathrm{Ca}_{\mathrm{v}} 1.2-1.3$ channels to net inward current in the interspike interval (Bevan and Wilson, 1999), although no effects on the frequency of autonomous activity were observed (WSR test; control $=14.6 \pm 2.2$ $\mathrm{Hz}$; nifedipine $=14.1 \pm 2.3 \mathrm{~Hz} ; n=15 ; p=0.6909)$. In contrast to the effects of apamin or $\omega$-conotoxin GVIA, nifedipine had no effect on the primary range but consistently shifted the secondary range of the $f-I$ relationship to the right, i.e., there was a reduction in the sensitivity of high-frequency firing to current injection
(Fig. 13C,D). This manifested itself as a significant increase in the normalized current to achieve half-maximal firing (WSR test: $1.1 \pm 0.039 ; n=11 ; p=0.01)$ and a significant decrease in the normalized slope of secondary range (WSR test: $0.76 \pm 0.049$; $n=11 ; p=0.0044$ ) (Fig. 13D). The effects on autonomous (M-W $U$ test; short-duration: $\mathrm{CV}=0.081 \pm 0.024, n=3$; longduration: $\mathrm{CV}=0.093 \pm 0.014, n=6 ; p=0.6056)$, driven activity (M-W U test; short duration: normalized current for half maximal firing $=1.21 \pm 0.054, n=3$; long-duration: normalized current for half maximal firing $=1.11 \pm 0.073, n=8 ; p=$ 0.2967 ), and the gradient of secondary range firing (M-W $U$ test; short-duration: normalized slope of the secondary range $=$ $0.77 \pm 0.005, n=3$; long-duration: normalized slope of the 
secondary range $=0.69 \pm 0.09, n=5 ; p=0.1797$ ) were similar in neurons with either short or long-duration rebound bursts. These data suggest that because $\mathrm{Ca}_{\mathrm{v}}$ 1.2.-1.3 channels are weakly coupled to SK $\mathrm{K}_{\mathrm{Ca}}$ channels, they can generate a net inward current that contributes to the higher sensitivity of the secondary firing range in STN neurons.

The effects of nifedipine on rebound burst activity were quite different from the effects of apamin or $\omega$-conotoxin GVIA treatment. No effect of nifedipine on the duration of rebound activity was observed in neurons with short-duration rebounds (WSR test; control $=47.4 \pm 11.7 \mathrm{msec}$, nifedipine $=42.4 \pm 12.8 \mathrm{msec}$, $n=5, p=0.6858$ ) (Fig. 13E,F). In contrast, nifedipine dramatically reduced the duration of rebound activity in neurons with long-duration rebound bursts (WSR test; control $=686.7 \pm$ $241.3 \mathrm{msec}$; nifedipine $=237.1 \pm 59.3 \mathrm{msec}, n=7, p=0.028$ ) (Fig. 13G,H). However, the homogenization of rebound activity that was observed in the presence of apamin was not as complete in nifedipine, i.e., the duration of rebound activity in neurons with rebound bursts $>100 \mathrm{msec}$ duration in control media was not reduced to $<100 \mathrm{msec}$ by nifedpine, which suggests that the channels underlying the early phase of the rebound depolarization may be differentially expressed or controlled by SK $\mathrm{K}_{\mathrm{Ca}}$ channels. Taken together, the effects of nifedipine on the $f-I$ curve suggest that both short- and long-duration rebound bursting neurons possess nifedipine-sensitive $\mathrm{Ca}_{\mathrm{v}} 1.2-1.3$ channels, but these channels only contribute to rebound activity in neurons with long-duration rebounds. Because apamin treatment converts short-duration rebound bursting neurons into longduration rebound bursting neurons, $\mathrm{SK} \mathrm{K}_{\mathrm{Ca}}$ channels may be important in limiting the activation of $\mathrm{Ca}_{\mathrm{v}} 1.2-1.3$ channels in short-duration rebound bursts under normal conditions.

\section{Discussion}

\section{Autonomous rhythmic activity}

Whereas all reports concur that $\mathrm{Na}_{\mathrm{v}}$ channels are necessary for the autonomous, rhythmic, single-spike discharge of STN neurons in vitro, the influence of $\mathrm{SK} \mathrm{K}_{\mathrm{Ca}}$ and $\mathrm{Ca}_{\mathrm{v}}$ channels is more controversial (Nakanishi et al., 1987; Bevan and Wilson, 1999; Beurrier et al., 1999, 2000; Otsuka et al., 2001). Recent reports suggest that the use of gluconate in whole-cell recordings can exert a variety of relevant effects. These include a reduction in SK $\mathrm{K}_{\mathrm{Ca}}$ and $\mathrm{Ca}_{\mathrm{v}}$ channel currents (Zhang et al., 1994; Velumian et al., 1997). Bicuculline methiodide may also reduce the contribution of SK $\mathrm{K}_{\mathrm{Ca}}$ channels (Johnson and Seutin, 1997; Seutin et al., 1997). Using perforated patch recording and GABAzine, singlespike activity was observed in STN neurons after SK $\mathrm{K}_{\mathrm{Ca}}$ channel blockade, but the trajectory of the interspike interval was altered and accompanied by irregular firing. These results, together with data from imaging and $\mathrm{Ca}_{\mathrm{v}} 2.2$ channel blockade, support the suggestion that calcium influx, primarily via $\mathrm{Ca}_{\mathrm{v}} 2.2$ channels during and subsequent to action potential generation, activates SK $\mathrm{K}_{\mathrm{Ca}}$ channels that mediate a component of the single-spike afterhyperpolarization. Similar selective activation of SK $\mathrm{K}_{\mathrm{Ca}}$ channels by calcium flowing through $\mathrm{Ca}_{\mathrm{v}} 2.2$ channels has been observed previously (Viana et al., 1993; Davies et al., 1996; Pineda et al., 1998; Wolfart and Roeper, 2002). We propose that the interruption of autonomous activity by apamin or $\omega$-conotoxin GVIA was caused by increased inactivation of $\mathrm{Na}_{\mathrm{v}}$ channels in the absence of SK channel activity, which is consistent with an increase in spike threshold. Therefore, $\mathrm{SK} \mathrm{K}_{\mathrm{Ca}}$ channels facilitate the precision of autonomous activity in STN neurons and play a similar role in other neurons (Bennett et al., 2000; Pedarzani et al., 2000; Wolfart et al., 2001; Cingolani et al., 2002).
The slow time course of calcium transients following autonomous spikes is consistent with the operation of slowly deactivating $\mathrm{Ca}_{\mathrm{v}}$ channels. Low voltage-activated calcium channels that deactivate slowly and are activated by single-spikes are possible contributors (Chemin et al., 2002; Wolfart and Roeper, 2002). Another possibility is calcium entry via rapidly deactivating $\mathrm{Ca}_{\mathrm{v}}$ channels (Stewart and Foehring, 2001) and the subsequent release of calcium from intracellular stores (Wolfart and Roeper, 2002).

\section{Repetitive high-frequency firing}

At low frequencies of activity, somatic calcium levels tracked the generation of action potentials. At frequencies of activity $>10 \mathrm{~Hz}$ calcium levels accumulated, and the peak level of calcium was linearly related to firing frequency. Similar relationships have been found in other types of neuron (Helmchen et al., 1996; Wang, 1998). As firing frequency increases, SK $\mathrm{K}_{\mathrm{Ca}}$ channels are likely to be activated more tonically and influence the frequency rather than timing of spikes. Indeed, $\mathrm{SK} \mathrm{K}_{\mathrm{Ca}}$ channels or $\mathrm{Ca}_{\mathrm{v}} 2.2$ channel blockade increased firing rates in response to equivalent input but did not disrupt the pattern of driven activity. The initial "speed-up" and subsequent adaptation were unaltered by SK $\mathrm{K}_{\mathrm{Ca}}$ or $\mathrm{Ca}_{\mathrm{v}} 2.2$ channel blockade. The decline in driven activity during repeated cycles of current injection was also not apaminsensitive. These data are consistent with reports in other neurons that apamin-sensitive SK $\mathrm{K}_{\mathrm{Ca}}$ channels influence the frequency of driven activity but do not underlie spike-frequency adaptation (Lorenzon and Foehring, 1992; Viana et al., 1993; Gorelova and Reiner, 1996). In other neurons, adaptation and a long-lasting reduction in post-train excitability are mediated by apamininsensitive $\mathrm{K}_{\mathrm{Ca}}$ channels (Lancaster and Nicoll, 1987; Lorenzon and Foehring, 1992) that are not prominent in STN neurons.

The linearization of the $f-I$ relationship after $S K K_{\mathrm{Ca}}$ or $\mathrm{Ca}_{\mathrm{v}} 2.2$ channel blockade suggests that the relationship between firing frequency and SK $\mathrm{K}_{\mathrm{Ca}}$ channel activation is greater for primary than secondary range activity. However apamin-sensitive posttrain afterhyperpolarization accumulated as the frequency of preceding activity increased and did not saturate at the transition between primary and secondary range firing. Another possibility for the enhanced sensitivity of secondary range firing is therefore the activation of a persistent inward current at depolarized potentials. The linearization of the $f-I$ relationship after SK $\mathrm{K}_{\mathrm{Ca}}$ or $\mathrm{Ca}_{\mathrm{v}} 2.2$ channel blockade could therefore be produced by the relative depolarization of the interspike interval (in the primary range) to levels normally associated with secondary range firing. In support of this hypothesis (1) the characteristic concave interspike voltage trajectory of the primary range was replaced by a more convex/depolarized trajectory in apamin or $\omega$-conotoxin GVIA, (2) blockade of $\mathrm{Ca}_{\mathrm{v}} 1.2-1.3$ channels reduced the sensitivity of secondary range firing in control media, and (3) the foot of the activation curve of $\mathrm{Ca}_{\mathrm{v}} 1.2-1.3$ channels is in the subthreshold range (Song et al., 2000). $\mathrm{Ca}_{\mathrm{v}} 1.2-1.3$ channels may therefore be recruited by depolarization of the interspike voltage during SK $\mathrm{K}_{\mathrm{Ca}}$ or $\mathrm{Ca}_{\mathrm{v}} 2.2$ channel blockade or during the transition from low- to high-frequency activity in control media.

\section{Rebound burst firing}

Subthalamic neurons are heterogeneous with respect to their burst firing, which is elicited from potentials more hyperpolarized than those traversed during autonomous oscillation (Beurrier et al., 1999, 2000; Bevan et al., 2000, 2002; Otsuka et al., 2001). Most studies concur that the early component of rebound burst firing is driven in part by nickel-sensitive, rapidly inactivating 
channels that presumably belong to the $\mathrm{Ca}_{\mathrm{v}} 3$ class that are inactivated during autonomous activity and recover from inactivation during hyperpolarization. In addition, a subset of neurons exhibits long-duration bursts, the late phase of which is driven in part by $\mathrm{Ca}_{\mathrm{v}} 1.2-1.3$ channels (Beurrier et al., 1999; Song et al., 2000; Otsuka et al., 2001). Our imaging studies confirm that subthreshold rebound activity is indeed associated with influxes of calcium. Despite this consensus, different roles have been concluded for the manner in which calcium dynamics influence rebound activity. In one report, intracellular BAPTA shortened rebound activity, a finding that has been interpreted to mean that calcium entry activates nonspecific cation channels that in part underlie long-duration rebound activity (Beurrier et al., 1999). In another report, intracellular BAPTA extended rebound activity, a finding that has been interpreted to mean that calcium entering during rebound activity activates potassium channels, which truncate rebound activity (Otsuka et al., 2001). However, the introduction of alien calcium chelators can have a variety of effects, which increase the difficulty of interpretation (Neher and Augustine, 1992; Helmchen and Tank, 1999). The findings of our study are consistent with the view that calcium entry during rebound activity activates $\mathrm{SK} \mathrm{K}_{\mathrm{Ca}}$ channels, which reduce the duration and intensity of rebound activity. Surprisingly, SK $\mathrm{K}_{\mathrm{Ca}}$ channels were much more effective in reducing rebound activity in neurons with short-duration bursts. However the magnitude of apamin-sensitive single-spike afterhyperpolarization and the effects of apamin on autonomous and driven firing were not significantly different in neurons with short- or long-duration rebound bursts, suggesting that the manner and magnitude of SK $\mathrm{K}_{\mathrm{Ca}}$ channel activation is more heterogeneous for rebound than repetitive activity. Our findings suggest that the strength of coupling of SK $\mathrm{K}_{\mathrm{Ca}}$ channels to $\mathrm{Ca}_{\mathrm{v}} 3$ channels (a source of calcium relatively untapped during repetitive activity), rather than the differential expression of $\mathrm{Ca}_{\mathrm{v}} 1.2-1.3$ or calcium-activated nonspecific cation channels or differential coupling to $\mathrm{Ca}_{\mathrm{v}} 2.2$ channels underlies rebound diversity. Strong coupling of SK $\mathrm{K}_{\mathrm{Ca}}$ channels and $\mathrm{Ca}_{\mathrm{v}} 3$ channels has also been observed in other neurons (Wolfart and Roeper, 2002). The powerful augmentation of rebound burst firing after $\mathrm{SK} \mathrm{K}_{\mathrm{Ca}}$ channel blockade also facilitated a switch from autonomous single-spike activity to rhythmic bursting in STN neurons. This pattern of activity had previously only been recorded reliably in whole-cell recordings that used gluconate and/or bicuculline methiodide (Beurrier et al., 1999, 2000, 2001; Baufreton et al., 2001, 2003).

\section{Functional implications}

Subthalamic neurons exhibit firing properties that are likely to contribute to their function and dysfunction in vivo. Autonomous single-spike activity, which may contribute to the function of STN neurons as a driving force of activity in the basal ganglia in vivo (Wichmann et al., 1994), is less regular in the absence of SK $\mathrm{K}_{\mathrm{Ca}}$ channels. As the precise timing of action potential generation is important for neural coding (Rieke et al., 1999), synaptic perturbation of autonomous activity (Bevan et al., 2002) is a potential mechanism by which STN neurons encode information. Such a proposal would be untenable if autonomous activity was inherently stochastic.

SK $\mathrm{K}_{\mathrm{Ca}}$ channels also maintain the low-sensitivity of STN neurons at frequencies associated with quiet wakefulness and confer a high-pass filtering property that only permits the transition to high-sensitivity, high-frequency activity during concerted/synchronous excitatory input that is presumably associated with movement (Kitai and Deniau, 1981; DeLong et al., 1985; Mat- sumara et al., 1992; Fujimoto and Kita, 1993; Wichmann et al., 1994; Bevan et al., 1995; Mouroux and Feger, 1995; Maurice et al., 1998a,b; Magill et al., 2000, 2001). SK $\mathrm{K}_{\mathrm{Ca}}$ channels are also critical for maintaining rebound diversity, although the significance of this property is unclear at the present time. Finally, because burst activity is more pronounced in STN neurons in PD (Bergman et al., 1994; Levy et al., 2000, 2002) and bursts are strongly regulated by $\mathrm{SK} \mathrm{K}_{\mathrm{Ca}}$ channels, the dopaminergic modulation of SK $\mathrm{K}_{\mathrm{Ca}}$ channels (Alexander et al., 2002) and their coupled $\mathrm{Ca}_{\mathrm{v}}$ channels (Catterall, 2000) may be of pathophysiological significance.

\section{References}

Abe Y, Furukawa K, Itoyama Y, Akaike N (1994) Glycine response in acutely dissociated ventromedial hypothalamic neuron of the rat: new approach with gramicidin perforated patch-clamp technique. J Neurophysiol 72:1530-1537.

Aizenman CD, Linden DJ (1999) Regulation of the rebound depolarization and spontaneous firing patterns of deep nuclear neurons in slices of rat cerebellum. J Neurophysiol 82:1697-1709.

Alexander JC, Barnwell LF, Schrader LA, Pfaffinger PJ, Sweatt JD, Anderson $\mathrm{AE}$ (2002) PKA phosphorylates the small conductance $\mathrm{K}^{+}$channel subunit, SK2. Soc Neurosci Abstr 22:217.6.

Barry PH (1994) JPCalc: a software package for calculating liquid junction potential corrections in patch-clamp, intracellular, epithelial and bilayer measurements and for correcting junction potential measurements. J Neurosci Methods 51:107-116.

Baufreton J, Garret M, Dovero S, Dufy B, Bioulac B, Taupignon A (2001) Activation of GABA(A) receptors in subthalamic neurons in vitro: properties of native receptors and inhibition mechanisms. J Neurophysiol $86: 75-85$.

Baufreton J, Garret M, de la Calle A, Gonon F, Dufy B, Bioulac B, Taupignon A (2003) D5 (not D1) dopamine receptors potentiate burst-firing in neurones of the subthalamic nucleus by modulating an L-type calcium conductance. J Neurosci 23:816-825.

Benabid AL, Koudsie A, Benazzouz A, Piallat B, Krack P, Limousin-Dowsey P, Lebas JF, Pollak P (2001) Deep brain stimulation for Parkinson's disease. Adv Neurol 86:405-412.

Bennett BD, Callaway JC, Wilson CJ (2000) Intrinsic membrane properties underlying spontaneous tonic firing in neostriatal cholinergic interneurons. J Neurosci 20:8493-8503.

Bergman H, Wichmann T, Karmon B, DeLong MR (1994) The primate subthalamic nucleus. II. Neuronal activity in the MPTP model of parkinsonism. J Neurophysiol 72:507-520.

Beurrier C, Congar P, Bilouac B, Hammond C (1999) Subthalamic neurons switch from single-spike activity to burst-firing mode. J Neurosci 19:599-609.

Beurrier C, Bioulac B, Hammond C (2000) Slowly inactivating sodium current $\left(\mathrm{I}_{\mathrm{NaP}}\right)$ underlies single-spike activity in rat subthalamic neurons. J Neurophysiol 83:1951-1957.

Beurrier C, Bioulac B, Audin J, Hammond C (2001) High-frequency stimulation produces a transient blockade of voltage-gated currents in subthalamic neurons. J Neurophysiol 85:1351-1356.

Bevan MD, Wilson CJ (1999) Mechanisms underlying spontaneous oscillation and rhythmic firing in rat subthalamic neurons. J Neurosci 19:7617-7628.

Bevan MD, Francis CF, Bolam JP (1995) The glutamate-enriched cortical and thalamic input to neurons in the subthalamic nucleus of the rat. J Comp Neurol 361:491-511.

Bevan MD, Wilson CJ, Bolam JP, Magill PJ (2000) Equilibrium potential of $\mathrm{GABA}_{\mathrm{A}}$ current and implications for rebound burst firing in rat subthalamic neurons in vitro. J Neurophysiol 83:3169-3172.

Bevan MD, Magill PJ, Hallworth NE, Bolam JP, Wilson CJ (2002) Regulation of the timing and pattern of action potential generation in rat subthalamic neurons in vitro by GABA-A IPSPs. J Neurophysiol 87:1348-1362.

Bond CT, Maylie J, Adelman JP (1999) Small-conductance calciumactivated potassium channels. Ann NY Acad Sci 868:370-378.

Catterall WA (2000) Structure and regulation of voltage-gated $\mathrm{Ca}^{2+}$ channels. Annu Rev Cell Dev Biol 16:521-555.

Chemin J, Monteil A, Perez-Reyes, Bourinet E, Nargeot J, Lory P (2002) 
Specific contribution of human T-type calcium channel isotypes $\left(\alpha_{1 \mathrm{G}}\right.$, $\alpha_{1 \mathrm{H}}$ and $\alpha_{1 \mathrm{I}}$ ) to neuronal excitability. J Physiol (Lond) 540:3-14.

Cingolani LA, Gymnopoulos M, Boccaccio A, Stocker M, Pedarzani P (2002) Developmental regulation of small-conductance $\mathrm{Ca}^{2+}$-activated $\mathrm{K}^{+}$ channel expression and function in rat Purkinje neurons. J Neurosci 22:4456-4467.

Davies PJ, Ireland DR, McLachlan EM (1996) Sources of $\mathrm{Ca}^{2+}$ for different $\mathrm{Ca}^{2+}$-activated $\mathrm{K}^{+}$conductances in neurons of rat superior cervical ganglion. J Physiol (Lond) 495:353-366.

Debarbieux F, Brunton J, Charpak S (1998) Effect of bicuculline on thalamic activity: a direct blockade of $\mathrm{I}_{\mathrm{AHP}}$ in reticularis neurons. J Neurophysiol 79:2911-2918.

DeLong MR, Crutcher MD, Georgopoulos AP (1985) Primate globus pallidus and subthalamic nucleus: functional organization. J Neurophysiol 53:530-543.

Do MTH, Bean BP (2003) Subthreshold sodium currents and pacemaking of subthalamic neurons: modulation by slow inactivation. Neuron 39: $109-120$.

Dodt HU, D’Arcangelo G, Zieglgansberger (1999) Infrared videomicroscopy. In: Imaging neurons. A laboratory manual (Yuste R, Lanni F, Konnerth A, eds), pp 7.1-7.8. New York: Cold Spring Harbor Laboratory.

Dostrovsky JO, Lozano AM (2002) Mechanisms of deep brain stimulation. Mov Disord 17:S63-S68.

Faber ESL, Sah P (2002) Physiological role of calcium-activated potassium currents in the rat lateral amygdala. J Neurosci 22:1618-1628.

Fujimoto K, Kita H (1993) Response characteristics of subthalamic neurons to the stimulation of the sensorimotor cortex in the rat. Brain Res 609:185-192.

Grynkiewicz G, Poenie M, Tsien RY (1985) A new generation of calcium indicators with greatly improved fluorescence properties. J Biol Chem 260:3440-3450.

Gorelova N, Reiner P (1996) Role of afterhyperpolarization in control of discharge properties of septal cholinergic neurons in vitro. J Neurophysiol 75:695-706.

Helmchen F, Tank DW (1999) A single-compartment model of calcium dynamics in nerve terminals and dendrites. In: Imaging neurons. A laboratory manual (Yuste R, Lanni F, Konnerth A, eds), pp 33.1-33.11. New York: Cold Spring Harbor Laboratory.

Helmchen F, Imoto K, Sakmann B (1996) $\mathrm{Ca}^{2+}$ buffering and action potential-evoked $\mathrm{Ca}^{2+}$ signaling in dendrites of pyramidal neurons. Biophys J 70:1069-1081.

Hosseini R, Benton DCH, Dunn PM, Jenkinson DH, Moss GWJ (2001) SK3 is an important component of $\mathrm{K}^{+}$channels mediating the afterhyperpolarization in cultured rat SCG neurones. J Physiol (Lond) 535:323-334.

Ishii TM, Maylie J, Adelman JP (1997) Determinants of apamin and D-tubocurarine block in SK potassium channels. J Biol Chem 272:23195-23200.

Johnson SW, Seutin V (1997) Bicuculline methiodide potentiates NMDAdependent burst firing in rat dopamine neurons by blocking apaminsensitive $\mathrm{Ca}^{2+}$-activated $\mathrm{K}^{+}$currents. Neurosci Lett 231:13-16.

Kaneoke Y, Vitek JL (1996) Burst and oscillation as disparate neuronal properties. J Neurosci Methods 68:221-223.

Kitai ST, Deniau JM (1981) Cortical inputs to the subthalamus: intracellular analysis. Brain Res 214:411-415.

Kyrozis A, Reichling DB (1995) Perforated-patch recording with gramicidin avoids artifactual changes in intracellular chloride concentration. J Neurosci Methods 57:27-35.

Lancaster B, Adams PR (1986) Calcium-dependent current generating the afterhyperpolarization of hippocampal neurons. J Neurophysiol 55:1268-1282.

Lancaster B, Nicoll RA (1987) Properties of two calcium-activated hyperpolarizations in rat hippocampal neurons. J Physiol (Lond) 389:187-203.

Levy R, Hutchison WD, Lozano AM, Dostrovsky JO (2000) High-frequency synchronization of neuronal activity in the subthalamic nucleus of parkinsonian patients with limb tremor. J Neurosci 20:7766-7775.

Levy R, Ashby P, Hutchison WD, Lang AE, Lozano AM, Dostrovsky JO (2002) Dependence of subthalamic nucleus oscillations on movement and dopamine in Parkinson's disease. Brain 125:1196-1209.

Lev-Ram V, Miyakawa H, Lasser-Ross N, Ross WN (1992) Calcium transients in cerebellar Purkinje neurons evoked by intracellular stimulation. J Neurophysiol 68:1167-1177.

Lorenzon NM, Foehring RC (1992) Relationship between repetitive firing and afterhyperpolarizations in human neocortical neurons. J Neurophysiol 67:350-363.

Magill PJ, Bolam JP, Bevan MD (2000) Relationship of activity in the subthalamic nucleus-globus pallidus network to cortical electroencephalogram. J Neurosci 20:820-833.

Magill PJ, Bolam JP, Bevan MD (2001) Dopamine regulates the impact of the cerebral cortex on the subthalamic nucleus-globus pallidus network. Neuroscience 106:313-330.

Marty A, Neher E (1983) Exchange of cell content with pipette solution. In: Single-channel recording (Sakmann B, Neher E, eds), pp 113-114. New York: Plenum.

Matsumara M, Kojima J, Gardner TW, Hikosaka O (1992) Visual and oculomotor functions of monkey subthalamic nucleus. J Neurophysiol 67:1615-1632.

Maurice N, Deniau JM, Glowinski J, Thierry AM (1998a) Relationships between the prefrontal cortex and the basal ganglia in the rat: physiology of the corticosubthalamic circuits. J Neurosci 18:9539-9546.

Maurice N, Deniau JM, Menetrey A, Glowinski J, Thierry AM (1998b) Prefrontal cortex-basal ganglia circuits in the rat: involvement of ventral pallidum and subthalamic nucleus. Synapse 29:363-370.

Mouroux M, Hassani OK, Feger J (1995) Electrophysiological study of the excitatory parafascicular projection to the subthalamic nucleus and evidence for ipsi- and contralateral controls. Neuroscience 67:399-407.

Myers VB, Haydon DA (1972) Ion transfer across lipid membranes in the presence of gramicidin A. II. The ion selectivity. Biochim Biophys Acta 274:313-322.

Nakanishi H, Kita H, Kitai ST (1987) Electrical membrane properties of rat subthalamic neurons in an in vitro slice preparation. Brain Res 437:35-44.

Neher E (1992) Corrections for liquid junction potentials in patch-clamp experiments. Methods Enzymol 207:123-131.

Neher E, Augustine GJ (1992) Calcium gradients and buffers in bovine chromaffin cells. J Physiol (Lond) 450:273-301.

Otsuka T, Murakami F, Song W-J (2001) Excitatory postsynaptic potentials trigger a plateau potential in rat subthalamic neurons at hyperpolarized states. J Neurophysiol 86:1816-1825.

Overton PG, Greenfield SA (1995) Determinants of neuronal firing pattern in the guinea-pig subthalamic nucleus: an in vivo and in vitro comparison. J Neural Transm 10:41-54.

Pedarzani P, Kulik A, Muller M, Ballanyi K, Stocker M (2000) Molecular determinants of $\mathrm{Ca}^{2+}$-dependent $\mathrm{K}^{+}$channel function in rat dorsal vagal neurones. J Physiol (Lond) 527:283-290.

Pedarzani P, Mosbacher J, Rivard A, Cingolani LA, Oliver D, Stocker M, Adelman JP, Fakler B (2001) Control of electrical activity in central neurons by modulating the gating of small conductance $\mathrm{Ca}^{2+}$-activated $\mathrm{K}^{+}$ channels. J Biol Chem 276:9762-9769.

Pineda JC, Waters RS, Foehring RC (1998) Specificity in the interaction of HVA Ca ${ }^{2+}$ channel types with $\mathrm{Ca}^{2+}$-dependent AHPs and firing behavior in neocortical pyramidal neurons. J Neurophysiol 79:2522-2534.

Rieke F, Warland D, Bialek W (1999) Spikes: exploring the neural code. Cambridge: MIT.

Rouzaire-Dubois B, Scarnati E (1985) Bilateral corticosubthalamic nucleus projections: electrophysiological study in rats with chronic cerebral lesions. Neuroscience 15:69-79.

Rouzaire-Dubois B, Scarnati E (1987) Pharamacological study of the cortical-induced excitation of subthalamic neurons in the rat: evidence for amino acids as putative neurotransmitters. Neuroscience 21:429-440.

Sah P (1996) $\mathrm{Ca}^{2+}$-activated $\mathrm{K}^{+}$currents in neurones: types, physiological roles and modulation. Trends Neurosci 19:150-154.

Sah P, Faber ESL (2002) Channels underlying neuronal calcium-activated potassium currents. Prog Neurobiol 66:345-353.

Seutin V, Scuvee-Moreau J, Dresse A (1997) Evidence for a non-GABAergic action of quaternary salts of bicuculline on dopaminergic neurons. Neuropharmacology 36:1653-1657.

Song W-J, Baba Y, Otsuka T, Murakami F (2000) Characterization of $\mathrm{Ca}^{2+}$ channels in rat subthalamic nucleus neurons. J Neurophysiol 84:2630-2637.

Stewart AE, Foehring RC (2001) Effects of spike parameters and neuromodulators on action potential waveform-induced calcium entry into pyramidal neurons. J Neurophysiol 85:1412-1423.

Stocker M, Pedarzani P (2000) Differential distribution of three $\mathrm{Ca}^{2+}$. 
activated $\mathrm{K}^{+}$channel subunits, SK1, SK2, and SK3, in the adult rat central nervous system. Mol Cell Neurosci 15:476-493.

Stocker M, Krause M, Pedarzani P (1999) An apamin-sensitive $\mathrm{Ca}^{2+}$. activated $\mathrm{K}^{+}$current in hippocampal pyramidal neurons. Proc Natl Acad Sci USA 96:4662-4667.

Storm JF (1989) An after-hyperpolarization of medium duration in rat hippocampal pyramidal cells. J Physiol (Lond) 409:171-190.

Syme CA, Gerlach AC, Singh AK, Devor DC (2000) Pharmacological activation of cloned intermediate- and small-conductance $\mathrm{Ca}^{2+}$-activated $\mathrm{K}^{+}$channels. Am J Physiol Cell Physiol 278:C570-C581.

Velumian AA, Carlen PL (1999) Differential control of three afterhyperpolarizations in rat hippocampal neurons by intracellular calcium buffering. J Physiol (Lond) 517:201-216.

Velumian AA, Zhang L, Pennefather P, Carlen PL (1997) Reversible inhibition of $\mathrm{I}_{\mathrm{K}}, \mathrm{I}_{\mathrm{AHP}}, \mathrm{I}_{\mathrm{h}}$ and $\mathrm{I}_{\mathrm{Ca}}$ currents by internally applied gluconate in rat hippocampal pyramidal neurones. Pflügers Arch 433:343-350.

Vergara C, Latorre R, Marrion NV, Adelman JP (1998) Calcium-activated potassium channels. Curr Opin Neurobiol 8:321-329.

Viana F, Bayliss DA, Berger AJ (1993) Multiple potassium conductances and their role in action potential repolarization and repetitive firing behavior of neonatal rat hypoglossal motoneurons. J Neurophysiol 69:2150-2163.

Wang X-J (1998) Calcium coding and adaptive temporal computation in cortical pyramidal neurons. J Neurophysiol 79:1549-1566.

Wichmann T, Bergman H, DeLong MR (1994) The primate subthalamic nucleus. I. Functional properties in intact animals. J Neurophysiol 72:494-506.

Wigmore MA, Lacey MG (2000) A Kv3-like persistent, outwardly rectify- ing, $\mathrm{Cs}^{+}$-permeable, $\mathrm{K}^{+}$current in rat subthalamic nucleus neurones. J Physiol (Lond) 527:493-506.

Wilson CJ, Callaway JC (2000) Coupled oscillator model of the dopaminergic neuron of the substantia nigra. J Neurophysiol 83:3084-3100.

Wise SP, Murray EA, Gerfen CR (1996) The frontal cortex-basal ganglia system in primates. Crit Rev Neurobiol 10:317-356.

Wolfart J, Roeper J (2002) Selective coupling of T-type calcium channels to SK potassium channels prevents intrinsic bursting in dopaminergic midbrain neurons. J Neurosci 22:3404-3413.

Wolfart J, Neuhoff H, Franz O, Roeper J (2001) Differential expression of the small-conductance, calcium-activated potassium channel SK3 is critical for pacemaker control in dopaminergic midbrain neurons. J Neurosci 21:3443-3456.

Xia X-M, Fakler B, Rivard A, Wayman G, Johnson-Pais T, Keen JE, Ishii T, Hirschberg B, Bond CT, Lutsenko S, Maylie J, Adelman JP (1998) Mechanism of calcium gating in small-conductance calcium-activated potassium channels. Nature 395:503-507.

Zhang L, Weiner JL, Valiante TA, Velumian AA, Watson PL, Jahromi SS, Schertzer S, Pennefather P, Carlen PL (1994) Whole-cell recording of the $\mathrm{Ca}^{2+}$-dependent slow afterhyperpolarization in hippocampal neurones: effects of internally applied anions. Pflügers Arch 426:247-253.

Zhang L, Pennefather P, Velumian A, Tymiansli M, Charlton M, Carlen PL (1995) Potentiation of a slow $\mathrm{Ca}^{2+}$-dependent $\mathrm{K}^{+}$current by intracellular $\mathrm{Ca}^{2+}$ chelators in hippocampal CA1 neurons of rat brain slices. J Neurophysiol 74:2225-2241.

Zhu Z-T, Shen K-Z, Johnson SW (2002) Pharmacological identification of inward current evoked by dopamine in rat subthalamic neurons in vitro. Neuropharmacology 42:772-781. 